\title{
Melatonin Beyond Its Classical Functions
}

\author{
Rüdiger Hardeland* and Burkhard Poeggeler
}

Johann Friedrich Blumenbach Institute of Zoology and Anthropology, University of Goettingen, Goettingen, Germany

\begin{abstract}
The perception of melatonin as a mediator of darkness, formed in a circadian fashion, circulating in subnanomolar concentrations, and removed as 6-sulfatoxymelatonin, reflects only a sector within a spectrum of actions. This ubiquitous compound present in bacteria and eucaryotes is exceptionally pleiotropic, in terms of binding proteins, receptor distribution, G protein coupling, electron-exchange reactions, and secondary effects by metabolites, such as 5methoxytryptamine and methoxylated kynuramines. Membrane receptors are located, e.g., in the vertebrate suprachiasmatic nucleus, pars tuberalis, brain, vasculature, and leukocytes. Binding proteins include quinone reductase 2, ROR/RZR transcription factors, calmodulin, calreticulin, nuclear and mitochondrial proteins. Actions via hormonal subsystems, growth factors, neurotransmission and immune system lead to further secondary effects. Single-electron transfer reactions are basis of radical scavenging, non-enzymatic metabolism and interactions with electron transport systems. The metabolite, $N^{1}$-acetyl-5-methoxykynuramine, is a potent inhibitor of prostaglandin synthesis and of neuronal NO synthase, an NO scavenger and a mitochondrial modulator.
\end{abstract}

Keywords: Aging, antioxidants, kynuramines, melatonin, neuroprotection, signal transduction.

\section{INTRODUCTION}

The indoleamine melatonin is perceived within the community mostly in a very limited context, in the role of a chronobiotic, which exhibits a circadian rhythm, is released at night from the pineal gland, transmits - as a troll among hormones - the signal darkness to other organs, in particular, to the suprachiasmatic nucleus (SCN) and, in seasonal breeders, to the eminentia mediana and pituitary. As a hormone, it is present in the circulation in usually subnanomolar concentrations. Considerable progress has been made concerning the regulation of its biosynthesis, its actions via membrane receptors and its chronobiological functions.

However, the exclusive consideration of this classical role is insufficient. Melatonin is a ubiquitous compound which has been found in any taxa studied so-far, including bacteria, eucaryotic unicellulars, macroalgae, plants, fungi as well as invertebrate and vertebrate animals [1-4]. In some of these organisms, the amounts of melatonin are remarkably high and exceed by orders of magnitude that what one is accustomed to find in vertebrates. Dinoflagellates exhibit basal levels between $20 \mathrm{nM}$ and $10 \mu \mathrm{M}$, but concentrations can rise dramatically in response to temperature changes and may transiently approach the millimolar range $[2,5,6]$. In yeast, melatonin levels depend on the availability of its precursor, tryptophan, and may rise to $40 \mu \mathrm{M}[2,7]$. Very high concentrations were detected in some vascular plants and, after such findings had been made especially in medicinal plants $[3,8,9]$, lists of 'record holders' were repeatedly published $[4,10-14]$. Since melatonin levels are highly variable among plant species, plant organs, fruits and seeds, the role of melatonin has to be diverse in these organisms [4]. Even

*Address correspondence to this author at the Johann Friedrich Blumenbach Institute of Zoology and Anthropology, University of Goettingen, Goettingen, Germany; Tel: +49-551-395414; Fax: +49-551-395438;

E-mail: rhardel@gwdg.de within the vertebrate body, melatonin concentrations can profoundly differ from those in the pineal gland and the circulation. Numerous extrapineal sites of melatonin synthesis exist, and in some of them, quantities or concentrations considerably exceed those in pineal and blood plasma [14-16]. In extrapineal sites, with exception of the retina and, where present, the parietal organ, circadian rhythms may exhibit low amplitudes or even be virtually absent, and the transmission of dark signals seems to be rather unlikely in organs like bone marrow or gastrointestinal tract. Again, the conclusion has to be that melatonin plays a number of different roles.

The multiplicity of melatonin's effects is remarkable, already within a vertebrate. Major areas of actions are schematically depicted in Fig. (1). These areas should not be seen as separate entities, but are rather overlapping in many details. The chronobiotic function of melatonin can influence each of them, but not necessarily at any site.

\section{MELATONIN AND ITS METABOLITES IN UNI- CELLS}

Melatonin has been demonstrated and measured in bacteria (Rhodospirillum, Erythrobacter and Escherichia coli), euglenoids, trypanosomids, ciliates, numerous dinoflagellates, and several chlorophyceans $[2,17]$. Though representing a secondary unicell, yeast (Saccharomyces) shall also be mentioned here [7]. In the majority of species, reliable determinations have been made, using safe extractions, calculations of recovery, and independent procedures, such as RIA and HPLC with electrochemical detection $[18,19]$. In addition to melatonin, its metabolites 5-methoxytryptamine (5MT) and 5-methoxytryptophol (5-ML) have been measured in dinoflagellates, in Euglena, in the ciliate Tetrahymena, and in yeast [2]. In a marine, bioluminescent dinoflagellate species, Lingulodinium polyedrum (syn. Gonyaulax polye$d r a)$, the formation of 5-methoxyindole-3-acetic acid (5- 


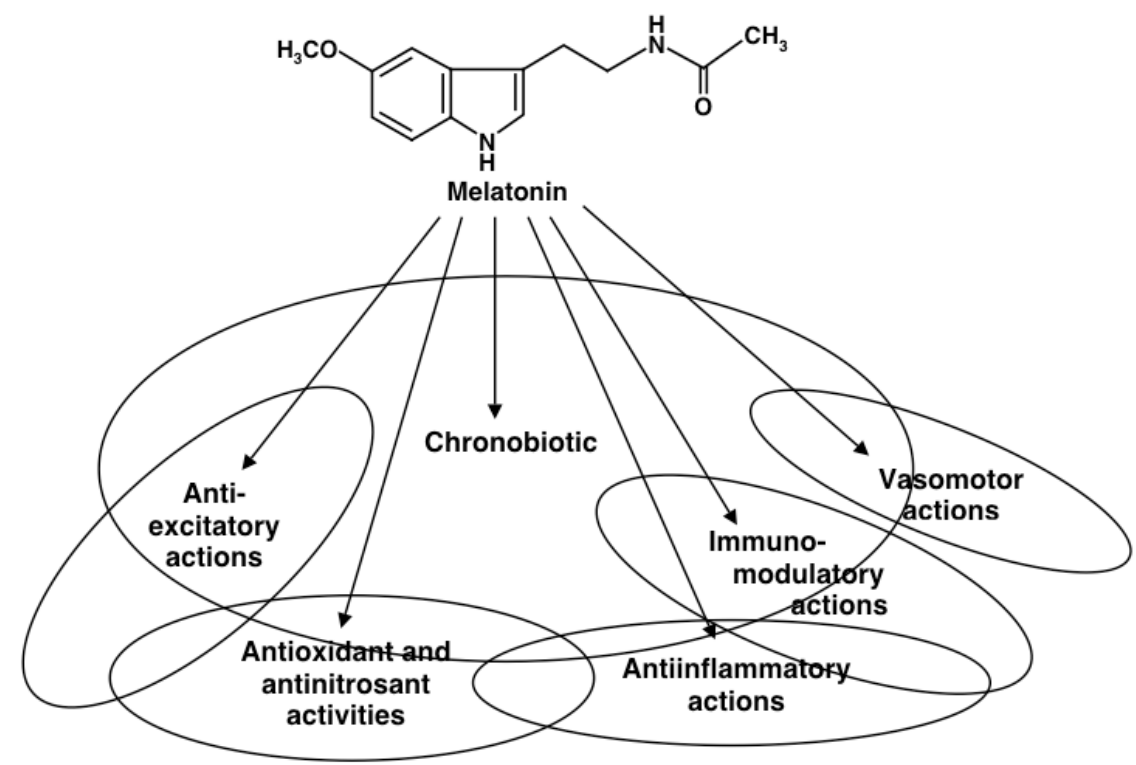

Fig. (1). The fields of melatonin's major actions. The chronobiotic actions are overlapping with all other functions, however, to a varying extent, as indicated by the graphic representation. Additional overlaps exist between some of the other areas of action. Interdependence and independence are depicted. For specific details see current text.

MIAA) [20-22], $N^{1}$-acetyl- $N^{2}$-formyl-5-methoxykynuramine (AFMK) [22-24] and pinoline [25] was also investigated.

Robust circadian rhythms of melatonin were discovered especially in L. polyedrum [18] and Euglena gracilis [2]. The rhythm in L. polyedrum persisted in constant darkness (DD) [23] and, contrary to the situation in vertebrates, also in constant light (LL) [26]. The latter finding is in accordance with strong rises observed in L. polyedrum when cells were subjected in LL to a decrease in temperature $[5,6]$. Differences in melatonin levels between light- and dark-exposed cells were also reported for the photosynthetic bacterium Erythrobacter longus [27] and, perhaps rhythmic, time patterns for chlorophyceans like Dunaliella and Chlamydomonas species, but details demonstrating a truly circadian periodicity have not been provided [2]. No rhythmicity was detected in yeast $[3,7]$, a finding which may be related to the absence of regulatory flanking regions in the arylalkylamine $\mathrm{N}$-acetyltransferase (AA-NAT) homolog [28]. In the ciliate Tetrahymena, melatonin was reported to be decreased by light, however, only gradually [29]. The most thoroughly studied rhythm, in L. polyedrum, is characterized by a steep rise directly after onset of darkness. In the course of the night, the melatonin level declines to almost basal values, largely because of deacetylation to 5-MT by an aryl acylamidase (AAA), which peaks, in coincidence with its product, $5-\mathrm{MT}$, during the last hours of dark phase $[26,30,31]$.

Where studied in detail, i.e., in Lingulodinium and in Saccharomyces, the pathway of melatonin biosynthesis is identical with that known from vertebrates, in a prevailing sequence of tryptophan $\rightarrow$ 5-hydroxytryptophan $\rightarrow$ serotonin $\rightarrow \mathrm{N}$-acetylserotonin $\rightarrow$ melatonin. Especially in Saccharomyces, a certain fraction of externally given 5-MT was reacetylated to melatonin, whereas exogenous melatonin was largely converted to 5-MT [7]. These findings are in good agreement with the usually observed relative substrate affinities of AA-NAT for serotonin and 5-MT, and also with those determined in L. polyedrum [32-34].
Contrary to vertebrates, which eliminate the circulating melatonin to a great deal by predominantly hepatic $\mathrm{P}_{450}$ monooxygenases (CYP1A2, CYP1A1, CYP1B1) and subsequent conjugation with sulfate, such a pathway designed for excretion would not be meaningful in aquatic unicells, which can easily release undesired compounds to the environment. Consequently, the main catabolic pathway is, in organisms like Lingulodinium and Saccharomyces, that one starting with deacetylation. In both species, 5-MT is further oxidized by a monoamine oxidase (MAO), to give 5-methoxyindole3 -acetaldehyde, which can be further converted by alcohol dehydrogenase to 5-ML, a compound found in these and other unicells. However, in Lingulodinium, the predominant fate of 5-methoxyindole-3-acetaldehyde is that of oxidation by aldehyde dehydrogenase to 5-MIAA, which is released from the cells, does practically not re-enter them from the relatively alkaline seawater and does not exhibit any demonstrable effect in this species [20-22]. 5-MT is also the likely source of pinoline found in L. polyedrum, as it is usually the case in other systems, including the mammalian and avian brain, retina and pineal [35-37]. Reactions of melatonin with free oxygen radicals, as they occur in any aerobic organism, and which are likely with this indoleamine owing to its remarkably high reactivity to radicals [38-40], are also possible in any of the unicells mentioned. A main product deriving from melatonin by radical-mediated or enzymatic pyrrole-ring cleavage, AFMK, was found in Lingulodinium, in particular as a consequence of photocatalytic reactions promoted by compounds present in the dinoflagellate [22-24].

A few responses and actions of melatonin have been identified in unicells. Tetrahymena was reported to increase and release melatonin in response to exogenously given small amount of this indoleamine, an effect interpreted as kind of an imprinting [41]. In Paramecium tetraurelia, melatonin increased the clonal life span [42]. One of the earliest effects reported for melatonin was detected in another ciliate, Stentor coeruleus, in which it interfered with the microtubu- 
lar arrangement in the cytostome field [43], an effect reminiscent of similar findings in plants and mammalian cells $[4,44]$. In the dinoflagellate Pyrocystis acuta, melatonin induced phase shifts in the circadian rhythm of spontaneous bioluminescence, and the phase response curve exhibited an advance part more pronounced than the delay part [2]. These results were obtained at concentrations of $100 \mu \mathrm{M}$, levels which are, however, attained in dinoflagellates $[2,5,6]$. In Lingulodinium polyedrum, melatonin did not show substantial phase shifts when cells were kept in constant dim light, but it moderately increased a phase advance induced by a light pulse at CT 15 (circadian time 15 h) [45]. However, in experiments not designated to phase shifting but rather to antagonize oxidative stress, moderate phase delays were repeatedly observed in DD [46]. Similar delays were observed in another member of this genus, L. spiniferum [2].

A chronobiological role of melatonin as a control factor rather than resetting agent seems to exist in the regulation of enzymes which oscillate in a circadian fashion. In L. polyedrum, melatonin downregulates two diurnally peaking enzymes, which oscillate with high-amplitude, tryptophan hydroxylase [30] and superoxide dismutase [46]. Another enzyme with a circadian maximum at onset of photophase, glutathione S-transferase, is moderately suppressed [46]. The findings on the two antioxidant enzymes profoundly differ from the situation in vertebrates, in which such components of the antioxidative protection system are usually upregulated by melatonin [47-49].

Another strong effect of high biological relevance for $L$. polyedrum is the upregulation of AAA [30]. The circadian melatonin peak after onset of darkness is followed with a certain delay by a maximum of AAA, which is causative for a corresponding peak in 5-MT, as already mentioned. Progressive rises in the amplitude of the AAA rhythm were observed when cells were subjected to a temperature step from 20 to $15^{\circ} \mathrm{C}[50]$, a treatment also leading to dramatic rises in melatonin levels, by orders of magnitude $[5,6]$. As a consequence of these increases in both melatonin and its catabolizing enzyme, AAA, strong elevations of 5-MT are observed [1,4-6].

The findings mentioned have considerable implications for the physiology and ecology of such dinoflagellates. Melatonin has been demonstrated to be not only a mediator of photoperiodic information, but also of temperature signals. This was also observed in Alexandrium lusitanicum and, however, as a response to high temperatures, in a tropical strain of Amphidinium carterae [4]. The extent of these temperature effects, as observed in dinoflagellates, exceeds by far moderate influences of temperature in any other organism studied.

Melatonin has turned out to generate high quantities of another bioactive molecule, 5-MT. In the dinoflagellates, 5MT is a signal molecule that is, under certain aspects, much more potent than the parent compound. Its primary action consists in the opening of proton channels in the membrane of acidic vacuoles $[1,4,23,33,34]$. Depending on the degree of stimulation by different 5-MT concentrations, this can have two consequences. At moderate concentrations, the intracellular, conducted proton potentials moving along the membrane of the acidic vacuoles of bioluminescent species initiate light emission by the entrance of protons into the microsources (scintillons), where they induce conformational changes in the luciferin-binding protein leading to luciferin release. By virtue of this mechanism, 5-MT is, contrary to melatonin, a very potent stimulator of bioluminescence in $L$. polyedrum $[23,33,51,52]$ and in several other species, too [2]. When 5-MT formation was blocked by inhibition of tryptophan hydroxylase or by oxidant-mediated destruction of methoxyindoles, the circadian peak of spontaneous bioluminescence was suppressed. This suppression was reverted by any metabolite leading to 5-MT, but not by other methoxyindoles, such as 5-ML [31,52-57]. Therefore, the glow peak, which coincides with the 5-MT maximum [26,31], was concluded to require the presence of physiologically elevated 5-MT levels.

Even higher 5-MT concentrations were obtained in Lingulodinium after a temperature drop leading to high melatonin and AAA induction. In this case, the massive proton transfer caused a cytoplasmic acidification, which was not seen with melatonin [23]. Similar acidifications were observed in other dinoflagellate species, too [2]. The decrease in cytosolic $\mathrm{pH}$ induced the formation of asexual cysts, a dormant state capable of surviving adverse conditions $[1,4,23,33,34,58-60]$. This effect was clearly attributable to proton transfer, since it was mimicked by any other means leading to cytoplasmic acidification, including protonophores, mechanical stress, low external $\mathrm{pH}$ and other acidifying agent such as epinephrine, another stimulator of bioluminescence $[23,33,60-62]$. Re-alkalinizations allowed cells to excyst again. Encystment in response to 5-MT was demonstrable in numerous dinoflagellates, whereas, in several other species not forming typical pellicle cysts, immobilization of still viable cells was observed [2].

\section{ROLES FOR MELATONIN IN PLANTS}

The presence of melatonin has now been shown in numerous plants and was repeatedly reviewed [1-4,8-14,63,64]. Despite the high number of demonstrations, the knowledge on physiological functions has remained remarkably scarce, mainly because investigators were less interested in plant physiology, but rather in finding nutritional or medicinal sources of the indoleamine many beneficial actions are ascribed to. A chronobiological role had been sought more or less in vain [4]. In a suitable test organism, Chenopodium rubrum, a nocturnally peaking circadian rhythm was described [65], but an involvement in photoperiodic short-day responses remained uncertain $[4,64]$. Likewise, no short-day responses were detected in some lemnaceans and in Kalanchoë tubiflora [4]. Rhythms reported for some other plants such as tomatoes were not confirmed, but rather changes during fruit ripening [66]. A well pronounced rhythm was described in the water hyacinth, Eichhornia crassipes [67]. In this species, the maximum was attained at the end of photophase, and the periodicity of melatonin was accompanied by another robust rhythm of the metabolite AFMK.

An auxin-like growth stimulation was found in both a dicot, Lupinus [68], and in monocots. Growth stimulation in coleoptiles of several poaceans was associated with another auxin-like action, growth inhibition of roots [69]. Whether these effects are physiologically relevant and whether melatonin metabolites may be involved, is an intriguing question 
to be answered in the future. The presence of particularly high melatonin levels in fruits and especially oily seeds indicated a possible role in differentiation processes and maintenance of dormancy, perhaps, in combination with antioxidative protection in dry seeds, in which enzymatic mechanisms cannot work $[4,70]$.

Radical reactions of melatonin are, of course, possible in any aerobic organism, the question is, however, that of rates and quantities. In Eichhornia, particularly high levels of AFMK were detected, which attained a maximum at the end of photophase, i.e., a time at which light-induced damage to photosystems and to auxiliary regenerating mechanisms are highest and, thus, oxidant formation [4]. This may indicate progressive oxidation of melatonin in the course of the light phase by free radicals, singlet oxygen, photocatalytically active compounds, peroxidases and/or other hemoproteins. Such melatonin-consuming reactions may, on the other hand, be regarded as contributions to photoprotection. A possible role in photoprotection had been assumed to be one of melatonin's functions in animal tissues, such as organs rich in photocatalytically active porphyrins like the rodent Harderian gland, in photoreceptors of some molluscs and crustaceans, and in several macro- and microalgae, too $[44,71]$. This may be similarly relevant to higher plants [4], as indicated by several observations: (i) light-dependent turnover of melatonin, (ii) UV-induced rises, and (iii) considerably higher melatonin contents found in plants exposed to high natural radiation, e.g., at alpine, mediterranean and subtropical sites, compared to same species in other locations or in greenhouses $[4,12]$.

\section{TISSUE MELATONIN IN VERTEBRATES}

With regard to actions beyond non-classical functions, extrapineal sites of melatonin formation in the vertebrate body deserve particular attention. Like the pineal gland, some of them also represent extrusions of the intermediate brain, such as the parietal organ of reptiles [72] and the retina of most vertebrates [73-84]. These organs exhibit robust, nocturnally peaking high-amplitude rhythms in melatonin, comparable to that found in the pineal gland. Insofar, they may appear as a variation of the same theme, but, except for retinas of amphibia and some other non-mammalian vertebrates, they contribute only poorly to the circulating hormone. Moreover, the presence [85], rhythmicity and release [86] of melatonin were shown in the rat hypothalamus, another area of the intermediate brain, but site-specific formation remains to be demonstrated.

The poor release from the mammalian retina clearly shows that melatonin serves, in this organ, other functions and is not or poorly acting as a hormone. In avian and mammalian retinas, melatonin strongly downregulates dopamine formation and release $[77,80,81]$. Contrary to the predominantly noradrenergic upregulation of melatonin biosynthesis in the mammalian pineal, retinal stimulation is mediated by a GABAergic mechanism, involving mainly $\mathrm{GABA}_{\mathrm{A}}$, but also partially $\mathrm{GABA}_{\mathrm{B}}$ receptors $[81,87]$. Melatonin and dopamine are obviously inversely correlated, because light, in turn, depresses retinal melatonin via dopamine $\mathrm{D}_{1}$ or $\mathrm{D}_{4}$ receptors [88-90]. In species in which melatonin is poorly released from the retina, it cannot be metabolized in the same way as the circulating hormone. In fact, is it largely converted to 5-MT, a finding which has even been made in amphibia, which liberate substantial amounts of melatonin [79,91-93]. Deacetylation by a specific melatonin deacetylase, as in the retina, but also by AAAs or an AAA-like activity of eserine-sensitive acetylcholinesterase are also relevant for the brain [16]. 5-MT, as a bioactive compound, exerts various effects in the central nervous system, as summarized in ref. [16], but the physiological relevance of respective pharmacological experiments is not always easy to judge. In cultured retinal cells, 5-MT was reported to prevent the forskolin-induced rise in cyclic AMP, in an action independent of melatonin receptors [94], a finding of still uncertain meaning.

Other areas in the central nervous system have also been suspected to be sources of melatonin [16]. This may be seen in relation to AA-NAT expression in various brain areas, which is, however, not necessarily associated with melatonin biosynthesis, because of separate central nervous actions of NAS and uncertainties concerning the presence of hydroxyindole $O$-methyltransferase, which may, however, be locally replaced by other methyltransferases [16]. Nevertheless, relatively high concentrations of about $0.7 \mu \mathrm{M}$ were reported for the whole mouse brain [95]. On the other hand, high concentrations of melatonin also enter the CNS from the pineal gland via the pineal recess $[96,97]$.

Melatonin synthesis was also described for the membranous cochlea, and smaller amounts of the indoleamine were found in the cochlear nerve of guinea pigs [98]. Temporal variations have been described, but data were not sufficient for describing a robust rhythm. The importance may be sought in protective actions within this highly vulnerable organ.

Several extrapineal sites of melatonin biosynthesis are devoid of robust circadian rhythmicity. In some of them, this has not been thoroughly studied yet. The rodent Harderian gland exhibits only weak diurnal changes, which may be almost absent. Usually, only a small, transient drop after onset of light is observed [99-103], which may not be of circadian nature. From these findings, the fundamental conclusion can be drawn that mammalian tissue melatonin is not necessarily associated with darkness. One could even suspect that light entering the Harderian gland might, by photocatalytic conversion to AFMK, create a signaling molecule perhaps indicative for the photophase. Variations in Harderian melatonin, as observed within sexual or seasonal cycles [99,101-103], do not indicate transmission of dark signals, but are rather a consequence of regulation by gonadosteroids, which strongly influence this gland [99,101,104-107].

The gastrointestinal tract is another, important site of melatonin formation, which has been reviewed several times [14,108-113]. The indoleamine is synthesized in the enterochromaffin cells, but circulating melatonin can be also taken up from the blood. Owing to its size, the entire gastrointestinal tract contains about $400-500$ times more of melatonin than the pineal gland $[110,111]$. The uptake of circulating melatonin has been demonstrated by elevating plasma melatonin during daytime to nighttime levels $[114,115]$. A substantial fraction was released unmetabolized from the gut to the lumen. In other studies, enterohepatic cycling of melatonin was demonstrated and, consequently, high quantities of 
the indoleamine were detected in the bile fluid $[113,116,117]$. As melatonin can enter the gut by reuptake from the lumen, its resorption from the food is not surprising. It is possible to elevate diurnal blood plasma levels by feeding vegetables rich in melatonin [118], whereas decreases were observed after melatonin-depleted food [119]. Whether intestinal bacteria also contribute to the melatonin content of the gut is a question that has been addressed [3], but is not yet solved.

Circadian rhythms have been described for gastrointestinal melatonin, but this should not be implicated in the transmission of dark signals. The amplitudes remain much lower than those in the pineal gland or the retina and usually attain maximum/minimum ratios of only $2: 1$ or lower, and may sometimes remain undetectable [14,110,111]. In some avian and mammalian species, the circadian peak of duodenal melatonin appeared earlier than that of the pineal gland $[85,120,121]$, a finding requiring further elucidation. This is possibly indicative of a relative independence of the gut from the pineal.

In the absence of a specific stimulus, gastrointestinal melatonin is poorly entering the circulation. However, it can be released into the blood, in response to food intake $[14,110,111]$ and, in particular, to high tryptophan $[113,122]$. The tryptophan-induced rise in plasma melatonin is higher than the nocturnal circadian peak originating from the pineal gland. The dramatic but transient melatonin surge from the gastrointestinal tract was reported to be unaffected by pinealectomy, but strongly diminished by partial portal ligature [122]. The physiological meaning of the postprandial melatonin release is poorly understood, but it should not be primarily a chronobiotic one. During daytime, melatonin released from the gut is almost ineffective because it appears mostly in the silent zone of the circadian phase-response curve [14]. Apart from the postprandial liberation to the blood, gastrointestinal melatonin seems to act largely through paracrine and luminal routes. It was shown to participate in the regulation of gastrointestinal motility $[110,111]$. Melatonin receptors have been identified in this organ [113]. Pharmacological experiments have also demonstrated cytoprotective, antioxidant and antiinflammatory actions as well as melatonin's efficacy in supporting wound healing and antagonizing esophagitis, gastritis, peptic ulcer, pancreatitis and colitis [113].

An organ that has been debated as another site of melatonin biosynthesis is the skin. The expression of enzymes required for melatonin formation has been demonstrated, such as tryptophan hydroxylase, AA-NAT and, as alternate enzymes, arylamine $N$-acetyltransferase (NAT) subforms, and HIOMT [123-128]. A major difficulty in judging the relevance of cutaneous melatonin results from discrepancies between levels measured in skin biopsies and in cultured keratinocytes. Earlier attempts of quantifying this indoleamine in skin samples by extraction and liquid chromatography techniques failed to demonstrate the presence of melatonin $[124,129]$, but this may have been a matter of safe extraction under avoidance of oxidative destruction, a problem that is present with various non-classical sources of melatonin [19]. On the other hand, cultured $\mathrm{HaCaT}$ keratinocytes were shown to contain remarkable amounts of about 30 $\mu \mathrm{M}$ melatonin (under consideration of an erratum) [130]. It seems rather unlikely - but is not impossible - that this entirely deviating result is only a consequence of a dysregulation in the cultured, immortalized cells.

Melatonin is believed to act as a photoprotective agent in the skin [126,130-132]. In HaCaT keratinocytes, oxidative metabolites, such as 6-hydroxy-, 2-hydroxy- and 4hydroxymelatonin and AFMK were also detected, and exposure to UVB caused rises in 2-hydroxymelatonin and AFMK [130]. It attenuated UV-induced apoptoses [131] and supported the maintenance of the mitochondrial membrane potential [132]. On the other hand, melatonin was reported to exert oncostatic effects in human melanoma cell lines [133]. Applicability in practice as an anti-cancer drug remains to be studied.

Several further tissues and cells have been reported to synthesize melatonin, such as the human ovary [134], bone marrow [135], in which the indoleamine was assumed to modulate hematopoiesis [136], various types of leukocytes [137-140], platelets [141], and even erythrocytes [142]. The role of the indoleamine in bone marrow, leukocytes and presumably also other cells relevant to the immune system seems to be of high relevance, as discussed in the section on multiple lines of defense. The formation in platelets and erythrocytes should not be overrated and may only reflect unavoidable side reactions taking place when plateletderived serotonin comes into contact with unspecific $N$ acetyl- and $O$-methyltransferases. Elevated concentrations of melatonin were detected in various other tissues, too $[140,143,144]$, but the alternative of biosynthesis $v s$. accumulation by uptake from the circulation remains to be clarified.

This overview on the presence, formation and functions of tissue melatonin shall be completed by addressing a few aspects of fundamental relevance. As briefly mentioned with reference to the mammalian retina, a poor release of melatonin to the circulation has two consequences. First, the indoleamine has to be metabolized differently from the circulating hormone, and routes of deacetylation to 5-MT or of pyrrole-ring cleavage to AFMK may be more important than hydroxylation or demethylation by CYPs. Second, the maintenance of elevated concentrations in a synthesizing but poorly secreting tissue requires an explanation. Because if its amphiphilicity, melatonin is usually believed to cross any membrane and, therefore, to reach any compartment or body fluid. In fact, externally administered melatonin is found soon in many places, but it does not equally distribute within the body $[114,115]$. Some organ systems such as the gut resorb relatively more melatonin than others. This observation may reflect the capacity of cells to maintain high concentrations by synthesizing but poorly releasing melatonin. If the assumption of passive diffusion through membranes is correct, the answer can be only sought in the presence of intracellular binding sites, which should be distinct from receptors but efficiently sequester the indoleamine. Results indicating melatonin retention were to date only obtained in the dinoflagellate Lingulodinium polyedrum $[21,143]$. Externally given melatonin accumulated intracellularly, for a couple of hours, to manyfold higher levels. Although the extracellular concentration did not substantially change because of a much 
larger medium volume compared to cell volume (about 2000:1), the accumulation ceased by time and was partially reverted. No indication existed for an active transport mechanism. In mammalian tissues, high amounts of melatonin were sometimes found in nuclei and mitochondria. Nuclear non-receptor binding proteins [144] may contribute to sequestration, for quantitative reasons [145].

\section{DIVERSITY OF ACTIONS BY DISTRIBUTION OF MEMBRANE RECEPTORS AND G PROTEINS}

Numerous melatonin bindings sites have been detected in CNS areas and many peripheral organs by means of the ligand $\left[{ }^{125} \mathrm{I}\right]$ iodomelatonin (summarized in ref. [44]). This reflects one aspect of the remarkable pleiotropy of this molecule. More specifically, the $\mathrm{G}$ protein-coupled membrane receptors $\mathrm{MT}_{1}$ and $\mathrm{MT}_{2}$, identified and analyzed in the pioneering work by SM Reppert and colleagues [146-153], are found in vertebrate tissues or cells. These include, e.g., retina, various brain areas, the hypothalamic median eminence, pituitary, choroid plexus, cerebral and peripheral vasculature, reproductive organs, adrenal cortex and several leukocytes [140,153-161]. In non-mammalian vertebrates, the receptor $\mathrm{Mel}_{1 \mathrm{c}}$ is present. For reasons of nomenclature, this receptor cannot be classified within the MT-terminology, and is not identical with a binding protein formerly called $\mathrm{MT}_{3}$.

Instead of listing all places in which $\mathrm{MT}_{1}$ and $\mathrm{MT}_{2}$ have been demonstrated, we shall focus on divergencies of actions mediated by these receptors. The classical, chronobiotic effects of melatonin, especially exerted in the circadian pacemaker, the $\mathrm{SCN}$, involve signaling via the $\mathrm{G}_{i}$ protein, leading in the case of $\mathrm{MT}_{1}$ mainly to acute suppression of neuronal firing, in that of $\mathrm{MT}_{2}$ predominantly to circadian phase shifts $[15,150-153,162-164]$. Since both actions are mediated by the same G protein and a decrease in cAMP, it is not surprising that these receptors can partially substitute for each other, as can be also seen in Sibirian hamster species, which do not possess the $\mathrm{MT}_{2}$ receptor, but respond to melatonin by phase shifts [165]. However, similar or synergistic actions by the two receptors are by no means universal, but rather depend on the relative expression of alternately coupling $G$ proteins as well on the effector proteins controlled by the various $\alpha$ subforms or by $\beta \gamma$. Therefore, effects mediated by $\mathrm{MT}_{1}$ or $\mathrm{MT}_{2}$ can be expected to be not only cell-specific, but also divergent if not antagonistic. In fact, such a complexity is observed. Co-activation or alternate activation of $\mathrm{G}_{\mathrm{o}}$ or $\mathrm{G}_{\mathrm{q}}$ has been repeatedly demonstrated $[153,154,157,166-169]$. In some cases, including studies in transfected cells, $G_{z}$ or $G_{16}$ were reported to differentially couple to melatonin receptors $[157,170,171]$. Contrary to decreases in cAMP caused by $\mathrm{G}_{\mathrm{i}}$ proteins, rises in cAMP were also described, e.g., for the Xenopus $\mathrm{Mel}_{1 \mathrm{c}}$ receptor when acting via $\alpha_{\mathrm{z}}$ coupling to adenylyl cyclase type II [172]. $\mathrm{G}_{\mathrm{i}}$-dependent mechanisms may not only affect cAMP levels, but also modulate, in some cells, $\mathrm{K}^{+}$conductance, and, via $\beta \gamma$, stimulate phospholipase $C \beta$ (PLC $\beta$ ), which may also occur with $G_{0}$ [157]. PLC $\beta$ activation seems to be a more general phenomenon of either parallel or alternate melatonin signaling present in various target tissues, including the SCN [173]. Both pertussis toxinsensitive $\left(\mathrm{G}_{\mathrm{i}} / \mathrm{G}_{\mathrm{o}}\right)$ and -insensitive (e.g., $\left.\mathrm{G}_{\mathrm{q}}\right) \mathrm{G}$ proteins can be involved [157,174-177]. The consequences of PLC $\beta$ activation are highly divergent, cell type-specific, and reach from stimulation of PKC subforms, CaM kinases, opening of $\mathrm{Ca}^{2+}$-activated $\mathrm{K}^{+}$channels to modulation of numerous other protein kinases, including the MAP and jun terminal kinase pathways. An extreme example for divergent actions mediated by $\mathrm{MT}_{1}$ and $\mathrm{MT}_{2}$ has been described for the vasomotor control by melatonin. While $\mathrm{MT}_{1}$ leads to a pertussis toxinsensitive vasoconstriction via opening of $\mathrm{BK}_{\mathrm{Ca}}$ channels, $\mathrm{MT}_{2}$ causes vasodilation $[16,153,178-181]$.

\section{NUMEROUS OTHER BINDING SITES}

The existence and physiological relevance of other binding sites has been vividly debated for quite some time. Meanwhile, their presence is beyond doubt. However, not all of them can be classified as receptors, especially when signaling mechanisms have not been demonstrated. One of these binding sites was originally named $\mathrm{MT}_{3}$ and believed to represent another membrane receptor. However, the protein is, in fact, the mainly cytosolic enzyme quinone reductase $2(=\mathrm{QR} 2=\mathrm{NRH}$ :quinone oxidoreductase $2=\mathrm{NQO} 2$; $\mathrm{NRH}=$ dihydronicotinamide riboside) [182-188]. QR2 is expressed in several tissues, including the brain $[183,189,190]$. It may be of interest that some of its polymorphic subforms have been related to Parkinson's disease [191], but, in mechanistic terms, the meaning of this finding is unclear. With regard to the activity of a quinone-reducing enzyme, a relationship to redox processes and detoxification seems likely, at first glance. However, the situation is not that simple. Disruption of the QR2 gene leads to bone marrow myeloid hyperplasia [192], indicating a function beyond detoxification of xenobiotics. Although a function in ubiquinone reduction was assumed, the precise role of this enzyme is not understood, especially with regard to the meaning of melatonin binding. Recently, melatonin has been suggested to act as a cosubstrate serving as a hydrogen/electron donor to other redox cofactors such as FAD [193], an assumption which seems possible with regard to melatonin's redox properties, but which would need direct experimental support. Perhaps, this discussion should not be exclusively focussed on melatonin, because $\mathrm{N}$-acetylserotonin, which is formed in many brain areas presumably without further $O$-methylation, has a similar affinity to QR2 [16]. Even without a convincingly demonstrated physiological role, QR2 may gain pharmacological relevance, since it is assumed to be a molecular target of resveratrol and of anti-malarian drugs such as chloroquin or paraquine [186].

Several other binding proteins are related to calcium signaling and distribution. One of them is calmodulin (CaM), which acts as a subunit and regulator of several protein kinases and other enzymes. Its affinity to melatonin is sufficient for mediating effects at elevated physiological concentrations, as attained in some tissues [194-197]. This may be also relevant for counteracting hyperphosphorylation-related cytoskeletal changes in neurodegenerative diseases [198]. Two enzymes of high physiological significance have been shown to be inhibited by melatonin via binding to $\mathrm{CaM}$, namely, CaM kinase II [196] and neuronal NO synthase $[44,199]$. In addition, melatonin causes PKC $\alpha$-dependent phosphorylation of calmodulin [200], presumably involving membrane receptors, an effect that reinforces and perpetuates CaM-dependent suppressions. Modulation of $\mathrm{CaM}$ and protein kinases mentioned are involved in cytoskeletal 
[195,197,198] effects, which extend from neuroblastoma cells to ciliates and plants $[1,44,195,198]$. Melatonin has been shown to act as a ligand of another important $\mathrm{Ca}^{2+}$ binding protein, calreticulin [144]. Additionally, a nuclear protein with high homology to calreticulin was discovered in that study, and another binding protein that was structurally different.

Another category of nuclear binding proteins can be classified as receptors in the proper sense. Although their affinity is lower than that of the membrane receptors, they may be relevant with regard to elevated melatonin concentrations in some tissues as well as to autocrine and paracrine effects. These proteins are the transcription factors $\mathrm{ROR} \alpha 1, \mathrm{ROR} \alpha 2$ and RZR $\beta$, which belong to the retinoic acid receptor superfamily [201-204]. Additional splice variants exist, but their relationship to melatonin is less clear. ROR $\alpha 1$ and $R O R \alpha 2$ seem to be involved in immunomodulation, in addition to the membrane receptors. RZR $\beta$ is especially expressed in the central nervous system, including the pineal gland $[15,16,140]$. ROR $\alpha$ was also assumed to participate in upregulations of antioxidant enzymes by melatonin [204].

A further melatonin binding site, with a dissociation constant of $150 \mathrm{pM}$ and a total number of specific binding sites of $30 \mathrm{fmol} / \mathrm{mg}$, has been detected in rat brain mitochondria [16]. Mitochondrial effects of melatonin on electron leakage from the respiratory chain indicate that this protein may be localized at the amphipathic ramp of complex I. Another mitochondrial action was only observed at elevated concentrations, namely a direct inhibition of the opening of the mitochondrial permeability transition pore [205], a finding that would imply another, low-affinity mitochondrial binding site.

\section{DIVERSITY OF METABOLISM AND ACTIONS OF METABOLITES}

As outlined in preceding sections, the metabolism of melatonin is taxon- and organ-dependent and not restricted to 6-hydroxylation. Deacetylation to 5-MT or demethylation to $\mathrm{N}$-acetylserotonin have been mentioned above. Effects of these bioactive compounds in vertebrates have been reviewed elsewhere [16]. Several other indolic compounds can derive from 5-MT, and some of them are biologically active, but, perhaps, only in a pharmacological or pathophysiological context. $\mathrm{N}, \mathrm{N}$-dimethyl-5-methoxytryptamine, formed from 5-MT or by $O$-methylation of bufotenin, is as an endogenous hallucinogen [16]. 5-ML, which can be formed from either 5-MT or 5-hydroxytryptophol, was shown in some species to vary in a diurnal and seasonal fashion, and to exert some antigonadal effects summarized elsewhere [25], which may, however, be inferior to those of melatonin. In one case, 5-ML was reported to be more efficient than melatonin, namely, in decreasing basal body temperature, an action shared with 5-hydroxytryptophol and $N$ acetylserotonin [206]. This potentially important finding has never been followed up. An almost forgotten melatonin ana$\log , O$-acetyl-5-methoxytryptophol, which can be formed from 5-ML and is present, e.g., in the pineal gland, was shown to inhibit nicotinic and muscarinic acetylcholine receptors and to decrease pituitary prolactin and LH [16].

Pinoline, a tricyclic compound belonging to the $\beta$ carboline family, is formed from 5-MT under uptake of a C- atom [35-37]. It is a natural metabolite, but a certain fraction is formed artificially during extraction, so that physiological levels remain uncertain. In the CNS, pinoline binding sites have been demonstrated, which may be identical with the imipramine binding site [207-210]. It does not only interfere with serotonin uptake, but also acts as a MAO A inhibitor $[211,212]$, thereby potentiating the enhancement of extracellular serotonin levels. The interference with extracellular serotonin availability can explain the neuro- and psychotropic effects of this compound, but this may be mainly a matter of pharmacology or, perhaps, of pathophysiology.

Another tricyclic metabolite is cyclic 3-hydroxymelatonin (c3OHM), a compound formed by sequential interaction of melatonin with two free radicals, under physiological conditions, two hydroxyl radicals [213-215]. After melatonin administration, it can be detected in the rodent urine [216], and it is strongly elevated after exposure to ionizing radiation [213]. With the exception of radical scavenging, no other effect of c3OHM is known to date.

Entirely different compounds, the 5-methoxylated kynuramines and their derivatives, are produced from melatonin upon cleavage of the pyrrole ring. The primary kynuramine metabolite, AFMK, is formed by numerous reactions ranging from enzymatic catalysis, by indoleamine 2,3-dioxygenase or by myeloperoxidase, to pseudoenzymatic mechanisms involving, e.g., hypervalent oxyferrylhemoglobin or hemin, to various photochemical and radical reactions [49, 217,218]. AFMK can be either formed (i) directly from melatonin, e.g., by the enzymes mentioned, by pseudoenzymatic reactions, by singlet oxygen, or (ii) by combination of an intermediate melatonyl radical with a superoxide anion, or (iii) from c3OHM, and, perhaps, also (iv) by 3-hydroxylation of 2-hydroxymelatonin. The broad spectrum of reactions leading to the same product, AFMK, is exceptional. Moreover, this kynuramine is frequently the major product formed in various oxidation systems, especially when they are not designed to generate a single radical species, but take account of the physiological prevalence of superoxide anions [49,219], which can serve as terminators of radical reaction chains [25,49]. In quantitative terms, AFMK formation has been underrated for a long time, partially because of the lack of sufficiently sensitive assays and availability problems. Although plasma and urinary amounts remained low in respective studies, even after oral administration of melatonin [216,220,221], one should not judge from these findings on the relevance of the pathway, which seems to be much more important in non-hepatic tissues. It would be a misconception to argue on the basis of circulating melatonin levels, because much higher amounts of the indoleamine are found outside the blood, quantities which are not generally entering the blood and are not preferentially hydroxlated. AFMK was demonstrable in the retina and in the lateral brain ventricle [221]. It also appeared in the blood after intraperitoneal melatonin administration [221]. Moreover, it was detected as a major brain metabolite exceeding by far the hydroxylated indolic metabolites [222]. Also with regard to its formation by myeloperoxidase, the AFMK route was assumed to contribute to about one third of total melatonin catabolism [223]. Furthermore, the high amounts of AFMK found in HaCaT keratinocytes [130] and in the plant Eichhornia [67] seem to shed light on the biological relevance of this compound. 
Attempts of identifying actions of AFMK were of limited success, when effects on the reproductive system [224,225] and affinities to benzodiazepine [226,227] and melatonin receptors $[228,229]$ were investigated. However, an interesting chronobiological effect of AFMK was described, which was never followed up later in other systems, namely, an acceleration of the reentrainment of the melatonin rhythm in rats [230]. More recently, the life cycles of malaria parasites (Plasmodium chabaudi and P. falciparum) were shown to be synchronized by AFMK in the upper nanomolar range, an effect associated with rises in cytosolic calcium [231]. However, this action was blocked by the $\mathrm{MT}_{1} / \mathrm{MT}_{2}$ antagonist luzindole [231], a finding raising the question of a direct or indirect interference of AFMK with melatonin receptors, despite the low affinities determined for direct binding of the kynuramine to the mammalian receptors.

Although cyclic voltammetry demonstrates a preference of AFMK for two-electron transfer reactions [217], so that the molecule is only a moderate radical scavenger [218,232], is has been used successfully for antagonizing oxidative damage and stress, however, at pharmacological concentrations. AFMK protected DNA from oxidative damage by hydroxyl radicals generated in a chromium(III)-based Fentonanalog reaction [233], or by a $\delta$-aminolevulinic acid $/ \mathrm{Fe}^{2+}$ system [234], but it remained less efficient than melatonin. AFMK reacts with this highly aggressive radical species, but rather moderately or even poorly with other radicals [218,232]. Nevertheless, protective effects by AFMK were observed in living cells, such as inhibition of toxicity by glutamate, $\mathrm{H}_{2} \mathrm{O}_{2}$, or amyloid $\beta_{25-35}$ peptide in hippocampal neurons [217], and, in mice exposed to X-rays, in which damage to DNA, proteins and lipids was attenuated [235]. AFMK was also reported to be a more efficient inhibitor of lipopolysaccharide (LPS)-induced formation of TNF- $\alpha$ and IL-8 in neutrophils, compared to melatonin [236], an effect which cannot be explained by affinity to free radicals released in response to LPS.

The discrepancy between moderate radical scavenging and potent protection may be explained in two different ways. Either the effects are caused by - to date unknown mechanisms modulating antioxidative enzymes or other protective proteins, or they imply the participation of less inert metabolites. In fact, the most frequently investigated product, $N^{1}$-acetyl-5-methoxykynuramine (AMK), is a much more potent radical scavenger $[218,232]$ and otherwise biologically active substance. AMK is formed by deformylation of AFMK, e.g., by arylamine formamidase (= kynurenine formamidase) $[14,25,49,218]$ or by hemoperoxidase ("catalase") [49,237] (Fig. 2). Recently another, photochemical mechanism by UV light has been described [238]. AMK formation may not be the exclusive route of AFMK metabolism, since oxidation reactions by free radicals led to a couple of $\mathrm{C} 2$-substituted 3-indolinones, which represent a novel class of oxidation products [239].

AMK is presumbly not just an end product, as previously believed, because it readily interacts with reactive oxygen species $[49,218,232]$, carbonate radicals [218,232], reactive nitrogen species, such as $\bullet \mathrm{NO}$ and nitroxyl (HNO) [240242], and is, therefore, rapidly consumed. Among the products, the stable, nitrosated derivative 3-acetamidomethyl-6- methoxycinnolinone (AMMC), formed by interaction with -NO or HNO [240-242] (Fig. 3), may be of particular interest, because other members of the cinnoline family have been used as medicaments or investigative drugs with antiallergic, antitumor, anxiolytic or other neurotropic properties [240].

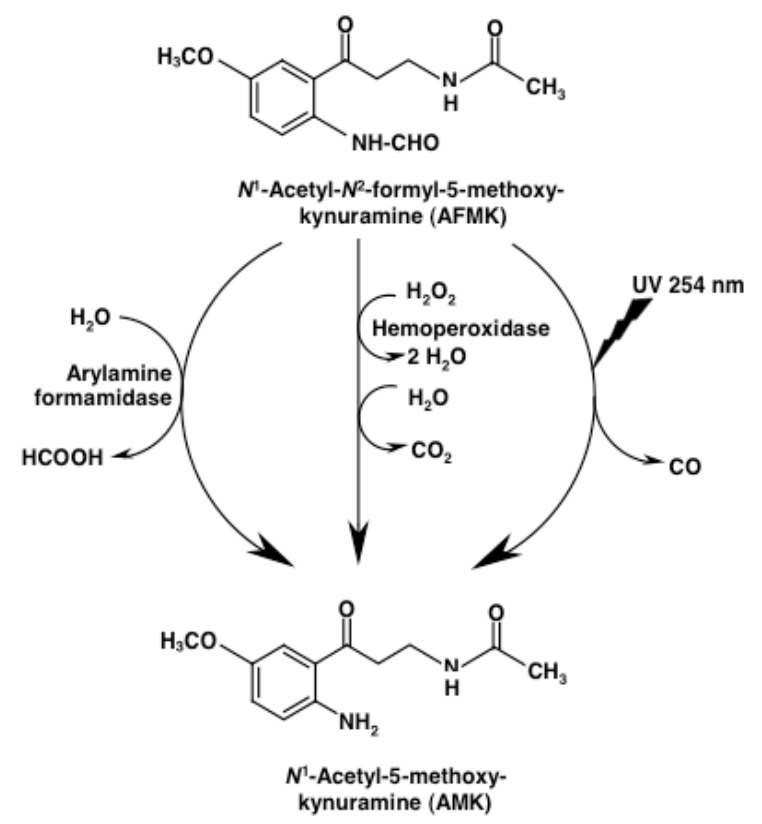

Fig. (2). Three pathways leading from the melatonin metabolite AFMK to the deformylated product AMK. For further details see refs. [49] and [238].

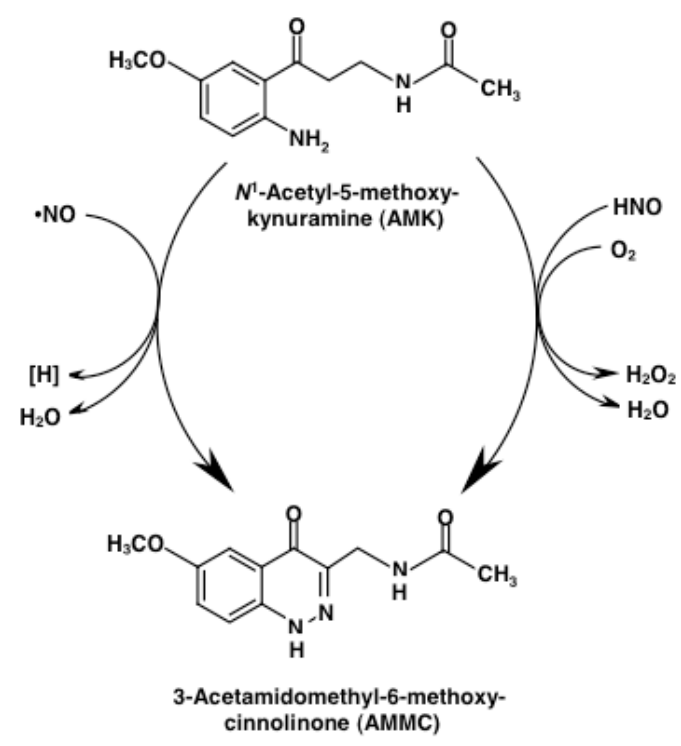

Fig. (3). Two pathways of AMK nitrosation, by the NO radical or by nitroxyl (HNO), lead to the same cinnolinone, AMMC. For further details see refs. [240-242]. The reaction with HNO includes two alternate possibilities differing in the sequence of consecutive steps [242]. A third pathway initiated by interaction of AMK with the nitrosonium cation $\left(\mathrm{NO}^{+}\right)$has been chemically identified [242], but is not depicted because it may be physiologically irrelevant with regard to the extremely short half-life of $\mathrm{NO}^{+}$in aqueous solution at neutral $\mathrm{pH}$. 
AMK itself also displays several potentially important pharmacological properties. It was reported to be a cyclooxygenase inhibitor by far more potent than acetylsalicylic acid (aspirin) [243]. More recently, AMK was shown to specifically downregulate, at pharmacological concentrations, cyclooxygenase- 2 expression in macrophages, but not that of cyclooxygenase-1 [244]. Effects observed in the nanomolar range concerning mitochondrial electron transport will be discussed next. Another action on neuronal NO synthase was also detected at very low concentrations [245]. This enzyme was demonstrably inhibited already at $10^{-11} \mathrm{M}$.

With regard to the biological activities of its metabolites, melatonin appears as a compound which does not exclusively display effects mediated by its own signaling mechanisms, but additionally represents a prodrug causing various secondary effects via its products [14]. Concerning AFMK and AMK, this should be seen in the context of the whole kynuramine family, an own class of biogenic amines, whose other members can be unsubstituted or hydroxylated at C-5, and methylated or dimethylated at N-1. Several effects of kynuramines have been summarized elsewhere [246].

\section{THE MULTIPLE LINES OF DEFENSE}

Protective effects have been ascribed to melatonin and some of its metabolites in numerous publications. However, many investigators solely focus on antioxidative actions such as radical scavenging to explain these actions. In fact, protection comprises several other mechanisms, which involve prevention of radical formation and different lines of defense (Fig. 1). Oxidative stress, which may be suppressed by pharmacological doses of melatonin, is frequently associated with other dysfunctions as a consequence and not the cause of disorders. In such cases, reversal of oxidative stress requires interference with the primary cause.

Already the chronobiotic actions of melatonin may contribute to the suppression of oxidative damage. Dysphased circadian rhythms and problems of coordination and coupling of oscillators are a potential source of oxidative stress. Enhanced oxidative damage to proteins and lipids was observed in clock mutants of Drosophila and Syrian hamster and is likely to occur upon repetitive phase shifting [247]. This view may be also in line with the observation that shortperiod mutations in clock genes can lead, in mice, to a cancer-prone phenotype [247-249]. Adjustment and appropriate coordination of rhythms may, thus, attenuate oxidative stress and damage to macromolecules. A second preventive action of melatonin to be discussed below in detail is that of antiexcitatory actions of melatonin in the CNS $[49,247]$. Antiexcitatory and antiexcitotoxic effects prevent excitationdependent calcium overload, secondary rises in radical formation, and antagonize mitochodrial dysfunction and cell death. Safeguarding of mitochondrial electron flux, attenuation of electron leakage and diminution of $\mathrm{Ca}^{2+}$-dependent -NO formation $[29,247]$ should be regarded as an important strategy for preventing mitochondrial dysfunction, as will be discussed in the subsequent section.

Another line of defense concerns the immune system. Since this aspect has been repeatedly reviewed in the last years $[15,140,250-256]$, only a general outline will be given. Melatonin is clearly an immunomodulatory agent, which not only acts on several types of leukocytes, but is also formed by some of them, such as monocytes, eosinophiles, mast cells and NK cells. Several leukocyte-derived cell lines were also shown to synthesize the indoleamine. Certain amounts found in thymocytes and epithelial cells [140] may be formed there or alternately taken up from the circulation. Various forms of leukocytes are activated by melatonin, in particular, T, B and NK lymphocytes, monocytes and splenocytes. These processes are associated with modulations of cytokine release and comprise stimulations of IL-2, IL-6 and IL-12 production, whereas levels of IFN $\gamma$ or TNF $\alpha$ were sometimes found to be decreased, but in other cases increased $[140,253,257]$. In the context of antiinflammatory aspects of immunomodulation, an inhibition of the $\mathrm{PGE}_{2}-$ induced suppression of IL-2 formation may be of particular interest $[139,153,258]$. Immunomodulation seems to be the result of concerted actions not only involving different cell types and their respective cytokines, but also different melatonin receptors. $\mathrm{MT}_{1}$ was found to mediate effects concerning IL-2, but the role of this receptor may extend to other functions, because the presence of this receptor was shown in numerous leukocyte subtypes [140,153,158,251]. Signaling via $\mathrm{MT}_{2}$ is involved in splenocyte proliferation and antagonizes leukocyte rolling $[153,259]$. In avian splenocytes, growth stimulation is mediated via the $\mathrm{Mel}_{\mathrm{lc}}$ receptor [260]. Leukotriene $\mathrm{B}_{4}$-induced endothelial leukocyte adhesion was ascribed to " $\mathrm{MT}_{3}$ " [259], but caution seems due because of the absence of signaling pathways known for QR2. ROR and RZR subforms are also expressed in various leukocytes and related cells such as splenocytes, thymocytes and Jurkat cells, and some of melatonin's immunological actions are assumed to be mediated by these transcription factors $[202,250,251,260]$. The coordinated actions of membrane and nuclear receptors in the immune system appear as an intriguing and potentially important field.

An aspect bridging immunological and antioxidant effects concerns the antiinflammatory actions of melatonin and its metabolite AMK. This is not limited to the suppression of proinflammatory prostaglandins, but extends to inhibition of - $\mathrm{NO}$ formation, scavenging of $\bullet \mathrm{NO}$ and attenuation of secondary oxidant, nitrosating and nitrating effects by this gaseous messenger and its metabolites, in particular, peroxynitrite [49]. Protective antiiflammatory actions involving $\bullet \mathrm{NO}$ metabolism have been reported to be efficient even in animals models of severe sepsis, such as cecal ligation and puncture [261-264].

In addition to the above-mentioned avoidance of radical formation, detoxification of free radicals and other oxidants may be regarded as another line of defense. The mechanisms involved are, again, multiple. At the level of gene expression, upregulations of antioxidative enzymes have been repeatedly described, in particular, of glutathione peroxidase [47-49,265-275], glutathione reductase [49,269,272,276], in some tissues, $\mathrm{Cu}, \mathrm{Zn}$ - and/or Mn-superoxide dismutases [47$49,271,272,273,275,277-280]$, catalase [48,49,275,281], and supporting enzymes that increase the availability of reduced glutathione, such as glucose-6-phosphate dehydrogenase $[47,49,269]$ and $\gamma$-glutamylcysteine synthase $[47,49]$. Prooxidant enzymes were shown to be downregulated, in particular, 5- and 12-lipoxygenases [47,49,282-284] and NO synthases $[44,47,49,270,285-293]$. The effects on 5- 
lipoxygenase were attributed to an ROR/RZR binding site in the promotor [202], and similar assumptions have been made for antioxidative enzymes [204]. However, the involvement of membrane receptors in the control of antioxidative enzymes was reported in other cases [294,295]. This issue urgently deserves clarification. Some further contributions to the defense in favor of oxidatively, nitrosatively or otherwise challenged cells seem to be related to signaling pathways and transcription factors. In murine macrophages, C6 glioma cells and skeletal muscle, downregulation of inducible NO synthase and, in glioma cells, cyclooxygenase-2, was shown to be associated with prevention of $\mathrm{NF \kappa B}$ activation [287,296,297]. Similar findings were obtained in the suppression of renal inflammation [298]. Inhibition of NFKB activation by melatonin was also observed in various models of oxidative stress [299-301], including A $\beta$ peptide toxicity [302] and brain trauma [303]. This antagonism to NFkB seems to be a general phenomenon, although it is not clear in each of these studies whether its activation is the result of intracellular rises in oxidants or signaling by cytokines, and at which level melatonin interferes. Melatonin-sensitive signaling cascades have not been studied extensively, and although the involvement of Akt [304], FAS ligand expression and c-Jun phosphorylation [305] have been occasionally shown, a coherent picture cannot be drawn yet, especially as these finding were made in contextual situations as different as inflammation, apoptosis and growth control.

Downregulation of steroid and related receptors by melatonin have been reported for several organs. Interference with the glucocorticoid receptor was decribed in thymus [306-308], brain (hippocampus, hypothalamus, cerebellum) [309-312], pituitary and liver [309,313], for thymus and cerebellum especially in terms of prevention of apoptosis. Similar downregulations were described for estrogen receptor $\operatorname{ER} \alpha$ and retinoic acid receptor $\operatorname{RAR} \alpha$ [314]. While the interference with these steroid and retinoic acid receptors is beyond doubt, the suppression mechanisms by which melatonin acts would require more experimental clarification. While some evidence was presented for the involvement of membrane receptors [310,314,315], an additional $\mathrm{MT}_{1}$ - and $\mathrm{ROR} \alpha$-independent mechanism was reported for thymocytes, which showed an inhibition of nuclear translocation of the glucocorticoid receptor [308]. Authors concluded on interference with Hsp90. This effect is not necessarily a direct one, but might have been mediated by immunophilins, as frequently observed in glucocorticoid resistance [316,317].

The last line of defense, that of direct radical scavenging, should be relevant only in the presence of high melatonin concentrations, for reasons of stoichiometry with radicals generated and proportions to other, usually more abundant antioxidants. This has been the case in numerous studies performed with pharmacological doses, but may be likewise valid for cells producing or storing elevated amounts of melatonin. This can be relevant for tissues like the rodent Harderian gland, for plants rich in melatonin as well as their seeds, and for some dinoflagellates. In Lingulodinium, elevated but physiologically possible concentrations of melatonin protected, without upregulation of antioxidative enzymes, against lethal oxidative stress by $\mathrm{H}_{2} \mathrm{O}_{2}$ [46] and sublethal stress by paraquat $[31,318,319]$.
Radical scavenging by melatonin has been reviewed several times [1,14,40,44,47,49,218,237,269,270,272,289], so that this will not be repeated here in any detail. As will be found there, melatonin scavenges with high efficacy hydroxyl radicals $(\cdot \mathrm{OH})$, some kinds of peroxyl radicals $(\bullet \mathrm{OOR})$, carbonate radicals $\left(\mathrm{CO}_{3}{ }^{-}\right)$, various radicals deriving from excited states of photocatalysts, other organic and some xenobiotic radicals. Superoxide anions $\left(\mathrm{O}_{2} \bullet^{-}\right)$are only scavenged at reasonable rates in the presence of enzymatic or pseudoenzymatic catalysts, or by melatonin's reactive radical intermediates, the melatonyl cation or neutral radicals. Melatonin can also interact with $\cdot \mathrm{NO}$ and $\cdot \mathrm{NO}_{2}$, whereas the frequently mentioned scavenging of peroxynitrite (which is highly reactive but not a radical) cannot be easily distinguished from the scavenging of peroxynitrite-derived radicals, which also lead to melatonin nitration. Although other indoles were sometimes reported to be similarly efficient as melatonin, this has to be seen with caution. It is particularly important that reactive intermediates from melatonin are capable of terminating radical reaction chains [49,219], thereby forming AFMK or c3OHM. Other indoles may scavenge free radicals at high rates, but the reaction chains are often not terminated so that the balance is a prooxidant one. Apparent rates of scavenging may also depend on the oxidation system. If this is designed in a way not easily allowing termination, e.g., in a chemist's attempt of studying the influence of a single radical species - which is highly unbiological - a prooxidant indole may appear as the "better" scavenger. If one considers, however, the physiological prevalence of superoxide anions, which terminate the radical chains, melatonin turns out to be superior to its structural analogs, in terms of antioxidative protection [320]. The oxidation chemistry of melatonin is clearly unique and not only dependent in the indole moiety, but strongly determined by both the 5-methoxy and the $N$-acetyl residues. While the effect of the methoxy group is not surprising, that of the acetyl group is estonishingly important, as demonstrated by conversion rates [320] and the formation of c3OHM [213]. With regard to the distance of this group from the aromate and to the possibility of forming a third ring, we assume the existence of a hydrogen bond between the acetyl-O and the pyrrole-N, which should also influence the $\mathrm{pK}$ of the melatonyl cation radical formed by single-electron donation. The cation radical is usually assumed to have a $\mathrm{pK}$ of about 4 and, thus, to readily form the neutral radical at physiological $\mathrm{pH}$ [215], but this conclusion is based on measurements with other indoles not forming such a bridge.

Although melatonin can eliminate in a scavenger cascade up to 10 free radicals [239], it does not do this in any situation. In the presence of an enzymatic (indoleamine 2,3dioxygenase) or pseudoenzymatic catalyst (hemin), just a single $\mathrm{O}_{2}{ }^{-}$molecule will be scavenged. Except for cells rich in melatonin, radical scavenging by this indoleamine may not suffice for quantitative elimination of oxidants, but still yield significant amounts of bioactive metabolites [49,247].

\section{ELECTRON TRANSFER REACTIONS AND THE ROLE IN MITOCHONDRIA}

Radical scavenging, as outlined above, reflects a property which should be of particular importance for melatonin's actions in mitochodria. As demonstrated by cyclic voltam- 
metry, melatonin displays a pronounced preference for single-electron transfer reactions [40]. What is otherwise seen in respective experiments as electron exchange with a free radical, may be something of more profound biological relevance in this organelle, namely, a basis for interactions with components of the electron transport chain. In this context, the pronounced amphiphilicity of melatonin may be decisive. This allows the molecule to enter the mitochondrion, and also to interact with components in an amphiphilic or even hydrophobic environment. The same is valid for its metabolite AMK. Moreover, melatonin has been shown to reduce cytochrome c [321] and cytochrome oxidase [322]. In both cases, AFMK was formed under the experimental conditions, and the action of cytochrome oxidase was interpreted as an atypical kind of peroxidase reaction, but, with regard to the preference for single-electron exchange, the initial step would be that of a one-electron donation, regardless of whether pyrrole-ring cleavage takes place in secondary reactions. However, the donation of electrons to the electron transport chain may, under physiological conditions, lead to other reactions, too, provided that the resonance-stabilized radical intermediates of melatonin are sufficiently stable. It was, therefore, assumed that melatonyl radicals might take up electrons again from iron-sulfur cluster N2 of complex I, which represents a bottleneck of electron flux and from where electrons are easily leaking out [247]. This may be similarly possible with an AMK-derived cation radical, so that both melatonin and AMK might create an electron shuttle bridging between the site of electron overflow and downstream sites of electron acceptance, thereby attenuating electron leakage to oxygen and formation of superoxide-derived oxidants in the mitochondrion $[14,49,247,323]$. Whether the action at $\mathrm{N} 2$ is sufficiently described by this model, remains to be analyzed in detail. Other data describing a mitochondrial high-affinity melatonin binding site [16] may indicate that the indoleamine exerts a regulatory function at the amphipathic ramp of complex I. Unlike other bioenergetic agents that modulate electron flux by substrate-specific stabilization of $\mathrm{N} 2$, such as theanine, melatonin appears to exert a ligand-specific stabilization. An interaction of melatonin with complex I, thereby supporting electron flux, was also observed in studies using MPTP/MPP ${ }^{+}[324,325]$.

A support of mitochondrial functions by melatonin has been repeatedly described in various models. In those based on intraorganellar changes, most of the data were obtained for submitochondrial particles. Such data do not reflect in vivo flux rates, but rather flux capacities. Nevertheless, a support of complex I and complex IV activities as well as rises in ATP formation were repeatedly observed, already at near-physiological concentrations [326-331]. The same was found with AMK in the nanomolar range [330]. Effects on activities of submitochondrial particles may either reflect enhanced stabilization of its components, by maintenance of active conformations or prevention of oxidative destruction, or enhanced de novo synthesis. The expression of subunits 1 - 3 of complex IV was, in fact, shown to be upregulated by melatonin [330]. Since eucaryotic gene expression requires time, but as mitochondrial effects are also seen in short-term experiments, this finding indicates another area of complexity of melatonin's actions. In fact, the situation is even more complicated insofar as melatonin also influences mitochon- drial glutathione [331] and $\cdot \mathrm{NO}$ formation and metabolism [261-264], factors which additionally modify the level of intramitochondrial oxidants and integrity of the components of the electron transport chain. The relevance of the interaction with such oxidants and prooxidants within the mitochondrion is supported by findings in septic mice, in which melatonin attenuated mitochondrial NO synthase activities and enhanced, at the same time, electron flux and ATP formation [261-264,332]. The interrelation between melatonin and changes in mitochondrial function are, moreover, of considerable gerontological interest, as will be discussed in a following section.

The preeminent role of mitochondria in the induction of apoptosis has been frequently studied and repeatedly reviewed $[49,331,333,334]$. Prevention of apoptosis was described many times, but the reasons for this may be diverse and depend on the mode of action of the respective inducers. In many cases, pharmacological doses of melatonin will have suppressed cell death by reducing damage by oxidants. In other cases, downregulation of $\bullet \mathrm{NO}$ formation or of signaling molecules such as NFKB may have been decisive. However, protection from apoptosis by agents interfering with the respiratory chain was achieved by melatonin, as summarized elsewhere [49]. In the future, it will be of particular importance to judge the significance of melatonin's direct effect on the mitochondrial permeability transitition pore [205] and the contribution of this effect to rescuing of cells in the respective models.

In summary, the mitochondrial actions of melatonin seem to profoundly exceed antioxidant effects and reflect bioenergetic control at key steps of electron and proton flux.

\section{ANTIEXCITOTOXICITY AND ANTICONVULSANT EFFECTS}

In the context of its chronobiotic actions, melatonin is involved in sleep initiation and phasing [15,335-337]. These effects, which are mediated through mechanisms involving the SCN and the hypothalamic sleep switch, are working in humans and diurnally active vertebrates, but not in the nocturnal animals, in which sleep is associated with photophase. However, sedating effects by melatonin are also found in nocturnally active species, such as rodents [338-341]. They have to be, therefore, different from the chronobiotic actions, although they are also subject to circadian variations. These findings extend to other, related influences of antiexcitatory/antiexcitotoxic, anticonvulsant, anxiolytic, antihyperalgesic and antinociceptive nature [15,339,340,342-346], which go beyond the chronobiotic and sleep-promoting activities. Melatonin-induced decreases in locomotor activity have been even found in Caenorhabditis elegans [347], an organism that does not exhibit a robust melatonin rhythm, but rather temporal fluctuations which are largely explained by melatonin uptake from its food, Escherichia coli [3]. Melatonin's sedating capacity may, thus, appear as an ancient property. However, detailed analyses in vertebrates reveal another remarkable complexity of antiexcitatory mechanisms, which involve modulations of signaling by GABA and glutamate receptors [346,348], secondary effects by decreases of cytosolic $\mathrm{Ca}^{2+}$ via $\mathrm{GABA}_{c}$ [349] or metabotropic $\mathrm{mGlu}_{3}$ receptors [350], interference with neuronal NO synthase, by melatonin or its metabolite AMK 
$[15,44,49,199,245,247,285,286]$, changes in $\mathrm{K}^{+}$currents [351], and potentiation of strychnine-sensitive glycineinduced currents [352]. Although the relative contributions of these mechanisms should be different in the various forms of antiexcitatory actions and also depend on CNS regions, the attenuation of neuronal excitation seems to be a general theme. These antiexcitatory and, moreover, antiexcitotoxic effects are not only important in terms of seizure prevention and treatment, but also one basis, amongst others, of radical avoidance and antiapoptotic activities [49].

It may be also noted that melatonin has been successfully applied in a couple of otherwise intractable cases of children with subtypes of epilepsy and West syndrome [353-355]. In a sense, this treatment may have been even a causal one, since very low baseline melatonin levels were found in some intractable patients with temporal lobe epilepsy [356]. In these subjects, strong rises in melatonin were observed following seizures [356], so that a relationship between melatonin dysregulation and overexcitation should be worth of further investigation.

\section{SECONDARY EFFECTS BY INFLUENCES ON OTHER HORMONAL AND NEURONAL SUBSYS- TEMS}

In its classical role as a hormone, melatonin is known to influence several important hormone systems, thereby initiating a host of secondary effects. In the context of seasonality, this has been extensively studied for the hypothalamicpituitary-gonadal axis. In other species undergoing a seasonal fattening cycle, similar observations have been made for the thyroid-directed axis. In terms of circadian regulation, melatonin participates in the phasing of high-amplitude hormonal rhythms, for which glucocorticoids give the most impressive example. These actions beyond the scope of this review extend, however, to other functions, in particular concerning the immune system, which is also subject to seasonal variations and in which melatonin interacts with thyroid hormones, glucocorticoids and, sometimes, gonadosteroids [357-362]. Melatonin influences further hormonal systems, too, in a presumably circadian fashion. $\mathrm{MT}_{1}$ receptors were recently demonstrated in both rat [363] and human [364] pancreatic islet cells. In the material from human islets, $\mathrm{MT}_{1}$ was expressed only in $\alpha$ cells, melatonin did not decrease cAMP, but stimulated glucagon secretion in $\mathrm{Ca}^{2+} \mathrm{i}^{-}$ dependent manner, presumably another case of alternate $\mathrm{G}$ protein coupling and regulation of PLC $\beta$. Signaling via $\mathrm{G}_{\mathrm{q}}$, PLC and $\mathrm{Ca}^{2+}$ is in accordance with another study [365]. Secondarily, the paracrine glucagon release stimulated insulin secretion, an otherwise well-known effect. The clinical relevance of interactions between melatonin and pancreatic hormones has been emphasized $[365,366]$.

Another area of high interest is the interaction of melatonin with molecules participating in neuronal communication. This has been addressed above for some neurotransmitter systems and for $\bullet \mathrm{NO}$, but likewise applies to neurotrophic factors. Colocalization of $\mathrm{MT}_{1}$ and expression of brainderived neurotrophic factor (BDNF) and glial cell linederived neurotrophic factor (GDNF) was demonstrated in glioma cells [367] and, more importantly, in neural and glial progenitor cells [368]. Moreover, melatonin was shown to stimulate the expression of these neurotrophic factors in stem cells [369]. Such findings may turn out to be of great value for maintenance and recovery of brain functions.

We are not aiming here to discuss the interactions of melatonin with any hormone, growth factor or other signaling molecule. However, it seems necessary to direct the investigators' attention to the numerous secondary effects melatonin exerts by modulating other communication systems within an organism and to the consequences thereof.

\section{MELATONIN, AGING AND NEURODEGENERATIVE DISORDERS}

The multiple protective actions of melatonin have been a reason for considering this indoleamine as a healthpromoting and potentially life-extending agent. While there can be no doubt about the beneficial effects concerning neuroprotection [36,198,270,323,370], the issue of life extension is a very particular one and should not be simply subsumed under the keyword of "anti-aging" with its, sometimes, nonscientific meaning. It is important to first perceive that a prolongation of lifetime, if it is observed, can have different causes and that the various model organisms and strains of them do not tell identical stories. If, e.g., a particular inbred mouse strain develops by age certain tumors from which the majority of animals die, melatonin's chemopreventive action rather than antagonization of aging in the proper sense is responsible for the effect observed. This has, in fact, been demonstrated in laboratory mice [371-373]. Moreover, the outcome of a melatonin treatment may be different in nocturnal and diurnal organisms, and the ability or non-ability to grow throughout life makes another difference. Life extension (mean and maximum life span) by the considerable amount of, at least $50 \%$, has been described in a gerontological model organism, the rotifer Philodina acuticornis $[373,374]$. Of course, this finding cannot be directly transmitted to vertebrate animals or to humans. Although several early studies in mammals may have suffered from methodological problems, and although some more recent evidence may still be circumstantial, anybody who has treated rodents with melatonin for extended periods of time will have observed the "Methusala syndrome" [374], i.e., the healthy condition of old melatonin-treated animals concerning mobility, glossy fur, absence of skin inflammations and low osteoporosis. Usually these animals die without a prolonged phase in poor health state.

A beneficial role in aging animals requires explanations, and, with regard to the extreme pleiotropy of melatonin, the answers are by far not self-evident or banal. Several consequences result from the various protective actions, and the respective areas are, again, overlapping and influencing each other (Fig. 4). As a result, they can finally contribute to healthy aging. Melatonin may already support good health conditions by influencing the circadian master clock, the SCN. Some indications for this may be found in a study on the aging degu, Octodon degus, a rodent from Chile, in which melatonin not only enhanced amplitude and activity/rest ratio of temperature and locomotor activity rhythms, but also led to a persistence of this effect after cessation of treatment [375]. This would require substantiation, also because some effect was already seen with the vehicle $(0.01 \%$ ethanol in drinking water). Nevertheless, this possibility of a chronobiologically based amelioration is not at all absurd. 


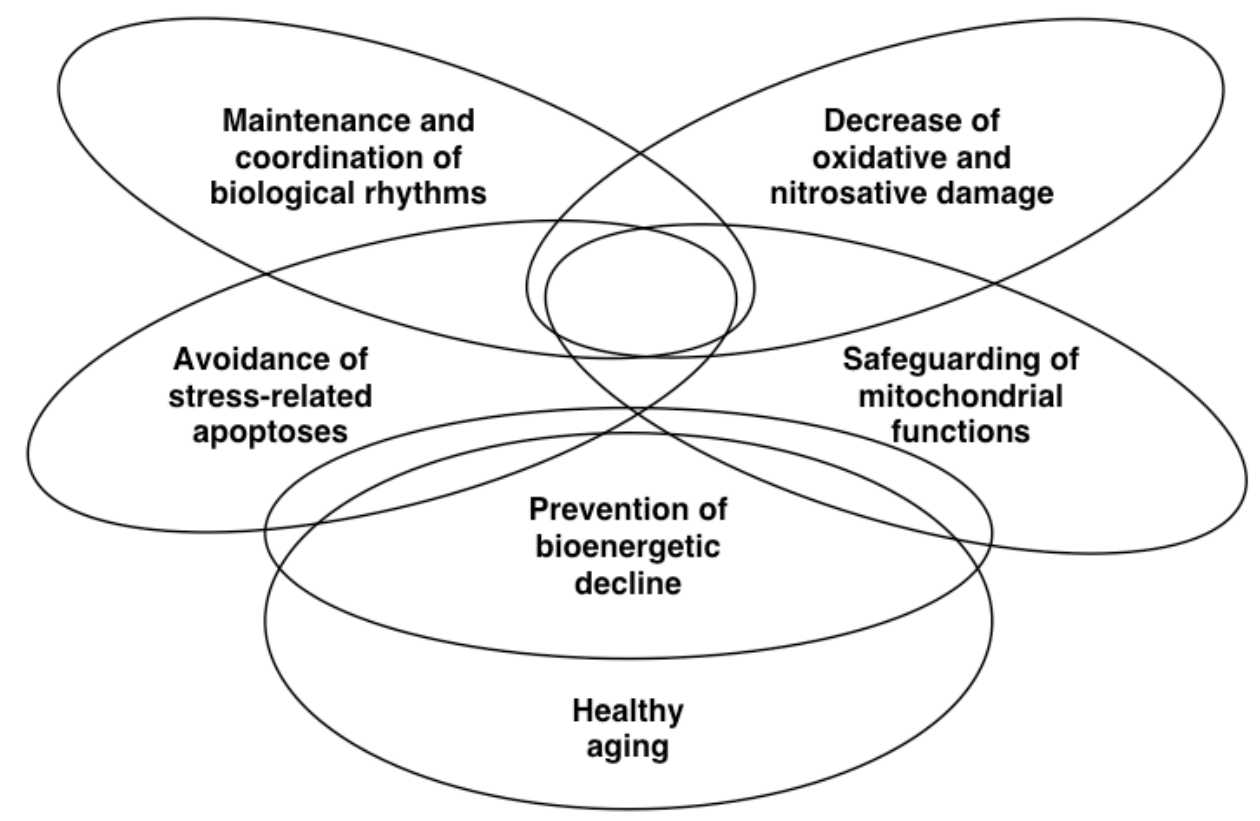

Fig. (4). The multiple consequences of melatonin's actions. Interrelations and mutual influences are indicated by the different degree of overlap, as depicted. The upper four areas comprise primary actions and are interrelated, as indicated by their specific intersections. Cell survival and mitochondrial function are basis for preventing bioenergetic decline, a universal feature of senescence.

Age-dependent declines in rhythmic functions [376] not only enhance morbidity and oxidative stress [247], but have been shown to be reverted by SCN transplantations, which also caused a certain extent of rejuvenilization [377].

Other actions of melatonin may contribute to an improved health state, too. Age-related inflammatory processes as well as susceptibility to inflammatory stimuli were demonstrated to be antagonized by melatonin in aged and, especially, senescence-accelerated rodents $[378,379]$. These finding may also extend to melatonin's immunomodulatory role in a broader sense. Amelioriations by attenuating oxidative and nitrosative stress have been repeatedly discussed [289,380,381]. More specifically, normalizations of mitochondrial functions including electron flux and ATP formation have been observed in old and senescence-accelerated mice [327-329,382], effects which may have considerably decreased oxidant formation $[49,247,383]$.

We do not want to advocate here a premature use of melatonin in aging humans, without knowing many more details required for a safe application, especially in diseased subjects. However, very high doses (suppositories, ca. 300 $\mathrm{mg}$ /day) over a year have been applied without complications in ALS patients [370]. The use of melatonin by elderly persons is, at least, worth of further, detailed investigation. This can be done, of course, only on the basis of controlled production and storage of melatonin preparations. Possibly impure pills sold over the counter and stored by the user under inappropriate conditions leading to chemical decay are unsuitable and potentially harmful.

\section{CONCLUSION}

The main message of this article can be summarized by three terms: ubiquity, pleiotropy and complexity. Ubiquity, which includes numerous, if not all, taxa of living beings, already implies diversity of actions, and only a small number of organisms ouside the vertebrates has been investigated in details of physiological relevance. Future investigators should not only intend to re-discover effects already known from mammals or birds, but orient themselves at the physiology and ecology of the respective organism.

Pleiotropy has multiple levels and facets. This includes the role as a pineal hormone, but the effects are not limited to sites as SCN, median eminence and pituitary, but extend to numerous organs or tissues. In this chronobiological function, melatonin exerts effects via other hormonal subsystems, growth factors, neurotransmitters and the immune network, which lead to further secondary effects. One can truly state that melatonin, in this role, orchestrates numerous rhythmic functions of the body, many of which have not been considered in classical investigations. The situation may be entirely different in extrapineal organs which also synthesize melatonin. Since the extrapineal amounts of this indoleamine exceed by far that in the pineal gland and the circulation, the relevance of tissue melatonin demands further research. Although considerable differences in temporal dynamics and metabolism have been demonstrated, important issues such as synthesis, turnover and retention have not been fully addressed yet.

Complexity starts with the different binding sites, some of which are receptors of varying affinity, and continues with cell-specific coupling to $\mathrm{G}$ proteins and other downstream effects. Moreover, melatonin is the parent compound of several bioactive metabolites, whose contribution to the spectrum of melatonin's actions deserves further clarification.

Temporal orchestration, pleiotropy and complexity are fascinating phenomena. On the other hand, they complicate investigations in intact organisms and may be regarded as a caveat concerning interpretations and undesired side effects, in both physiological experiments and pharmacological use. 


\section{REFERENCES}

[1] Hardeland R, Fuhrberg B. Ubiquitous melatonin - Presence and effects in unicells, plants and animals. Trends Comp Biochem Physiol 1996; 2: 25-45.

[2] Hardeland R. Melatonin and 5-methoxytryptamine in nonmetazoans. Reprod Nutr Dev 1999; 39: 399-408.

[3] Hardeland R, Poeggeler B. Non-vertebrate melatonin. J Pineal Res 2003; 34: 233-41.

[4] Hardeland R, Pandi-Perumal SR, Poeggeler B. Melatonin in plants - Focus on a vertebrate night hormone with cytoprotective properties. Funct Plant Sci Biotechnol 2007; 1: 32-45.

[5] Fuhrberg B, Hardeland R, Poeggeler B, Behrmann G. Dramatic rises of melatonin and 5-methoxytryptamine in Gonyaulax exposed to decreased temperature. Biol Rhythm Res 1997; 28: 144-50.

[6] Fuhrberg B, Hardeland R. Temperature as a major environmental factor controlling levels and rhythm amplitudes of melatonin in the marine dinoflagellate Gonyaulax polyedra. Biometeorology 1997; 14 (Pt 2/2): 272-77.

[7] Sprenger J, Hardeland R, Fuhrberg B, Han S-Z. Melatonin and other 5-methoxylated indoles in yeast: Presence in high concentrations and dependence on tryptophan availability. Cytologia 1999; 64: 209-13.

[8] Murch SJ, Simmons CB, Saxena PK. Melatonin in fever few and other medicinal plants. Lancet 1997; 350: 1598-9.

[9] Murch SJ, Saxena PK. A melatonin-rich germplasm line of St John's wort (Hypericum perforatum L.). J Pineal Res 2006; 41: 284-7.

[10] Manchester LC, Tan D-X, Reiter RJ, Park W, Monis K, Qi W. High levels of melatonin in the seeds of edible plants. Possible function in germ tissue protection. Life Sci 2000; 67: 3023-9.

[11] Reiter RJ, Tan D-X, Burkhardt S, Manchester LC. Melatonin in plants. Nutr Rev 2001; 59: 286-90.

[12] Conti A, Tettamanti C, Singaravel M, Haldar C, Pandi-Perumal RS, Maestroni GJM. In: Haldar C, Singaravel, Maitra SK, Eds. Melatonin: An ubiquitous and evolutionary hormone. In: Treatise on Pineal Gland and Melatonin. Science Publishers, Enfield, NH, 2002; 105-43.

[13] Chen G, Huo Y, Tan D-X, Liang Z, Zhang W, Zhang Y. Melatonin in Chinese medicinal herbs. Life Sci 2003; 73: 19-26.

[14] Hardeland R, Pandi-Perumal SR. Melatonin, a potent agent in antioxidative defense: Actions as a natural food constituent, gastrointestinal factor, drug and prodrug. Nutr Metab (London). 2005 Sept 10. 2: article no 22 [15 screens]. Available from: http://www.biomedcentral.com/1743-7075/2/22.

[15] Pandi-Perumal SR, Srinivasan V, Maestroni GJM, Cardinali DP, Poeggeler B, Hardeland R. Melatonin - Nature's most versatile biological signal? FEBS J 2006; 273: 2813-38.

[16] Hardeland R, Poeggeler B. Actions of melatonin, its structural and functional analogs in the central nervous system and the significance of metabolism. Cent Nerv Syst Agents Med Chem 2007; 7: 289-303.

[17] Balzer I, Höcker B, Kapp H, Bartolomaeus B. In: Vanden Driessche T, Guisset J-L, Petiau-de Vries GM, Eds. Occurrence and comparative physiology of melatonin in evolutionary diverse organisms. In: The Redox State and Circadian Rhythms. Kluwer, Dordrecht, 2000; 95-119.

[18] Poeggeler B, Balzer I, Hardeland R, Lerchl A. Pineal hormone melatonin oscillates also in the dinoflagellate Gonyaulax polyedra. Naturwissenschaften 1991; 78: 268-9.

[19] Poeggeler B, Hardeland R. Detection and quantification of melatonin in a dinoflagellate, Gonyaulax polyedra. Solutions to the problem of methoxyindole destruction in non-vertebrate material. $\mathrm{J}$ Pineal Res 1994; 17: 1-10.

[20] Mueller U, Hardeland R. In: Hardeland R, Ed. Methoxyindoles in Gonyaulax: Marked intracellular accumulations of exogenous 5methoxytryptamine and $N, N$-dimethyl-5-methoxytryptamine, formation and release of 5-methoxyindole-3-acetic acid. Implications for previous interpretations. In: Studies on Antioxidants and Their Metabolites. Cuvillier, Göttingen, 1999; 148-61.

[21] Mueller U, Hardeland R. Fuhrberg B, Poeggeler B. Accumulation and metabolism of 5-methoxylated indoleamines in the dinoflagellate Gonyaulax polyedra. Eur J Cell Biol 2000; 79, Suppl 50: 98.

[22] Mueller U, Hardeland R, Poeggeler, B, Fuhrberg B, Burkhardt S. Pathways of melatonin catabolism in the dinoflagellate Gonyaulax polyedra. Biol Rhythm Res 2001; 32: 465.
[23] Hardeland R, Balzer I, Poeggeler B, et al. On the primary functions of melatonin in evolution: Mediation of photoperiodic signals in a unicell, photooxidation and scavenging of free radicals. J Pineal Res 1995; 18: 104-111.

[24] Mueller U, Hardeland R. In: Hardeland R, Ed. Photooxidative pyrrole-ring cleavage of melatonin: limits of quantification. In: Studies on Antioxidants and Their Metabolites. Cuvillier, Göttingen, 1999; 162-171.

[25] Hardeland R, Reiter RJ, Poeggeler B, Tan D-X. The significance of the metabolism of the neurohormone melatonin: antioxidative protection and formation of bioactive substances. Neurosci Biobehav Rev 1993; 17: 347-357.

[26] Hardeland R. In: Fanjul-Moles ML, Aguilar-Roblero R, Eds. Melatonin and other tryptophan metabolites: Rhythms outside the animal world and some novel, presumably universal pathways. In: Comparative Aspects of Circadian Rhythms. Transworld Research Network, Trivandrum, 2008; 1-17.

[27] Tilden AR, Becker MA, Amma LL, Arciniega J, McGaw AK. Melatonin production in an aerobic photosynthetic bacterium: an evolutionarily early association with darkness. J Pineal Res 1997; 22: 102-6.

[28] Ganguly S, Mummaneni P, Steinbach PJ, Klein DC, Coon SL. Characterization of the Saccharomyces cerevisiae homolog of the melatonin rhythm enzyme arylalkylamine $N$-acetyltransferase (EC 2.3.1.87). J Biol Chem 2001; 276: 47239-47.

[29] Köhidai L, Vakkuri O, Keresztesi M, Leppäluoto J, Csaba G. Melatonin in the unicellular Tetrahymena pyriformis: effects of different lighting conditions. Cell Biochem Funct 2002; 20: 269-72.

[30] Hardeland R, Fuhrberg B, Burkhardt S, Poeggeler B, Lax P. Aryl acylamidase and tryptophan hydroxylase, two key enzymes of 5methoxytryptamine formation in the dinoflagellate Gonyaulax polyedra, are regulated by a circadian oscillator, by melatonin and by temperature. Biometeorology 1997; 14 (Pt 2/2): 278-85.

[31] Hardeland R, Burkhardt S, Antolín I, Fuhrberg B, Coto-Montes A. Melatonin and 5-methoxytryptamine in the bioluminescent dinoflagellate Gonyaulax polyedra: Restoration of the circadian glow peak after suppression of indoleamine biosynthesis or oxidative stress. Adv Exp Med Biol 1999; 460: 387-90.

[32] Balzer I, Hardeland R. Une réponse photopériodique chez le dinoflagellé Gonyaulax polyedra: le rôle possible des indoleamines. Bull Gr Et Rythmes Biol 1993; 25(4): 23-7.

[33] Hardeland R, Balzer I. Chronobiology of unicells: Multiplicity of frequencies, non-oscillatory states, photoperiodism and effects of biogenic amines. Trends Comp Biochem Physiol 1993; 1: 71-87.

[34] Hardeland R. The presence and function of melatonin and structurally related indoleamines in a dinoflagellate, and a hypothesis on the evolutionary significance of these tryptophan metabolites in unicellulars. Experientia 1993; 49: 614-22.

[35] Barker SA, Harrison RE, Monti JA, Brown GB, Christian ST. Identification and quantification of 1,2,3,4-tetrahydro- $\beta$-carboline, 2 -methyl-1,2,3,4-tetrahydro- $\beta$-carboline, and 6-methoxy-1,2,3,4tetrahydro- $\beta$-carboline as in vivo constituents of rat brain and adrenal gland. Biochem Pharmacol 1981; 30: 9-17.

[36] Kari I. 6-Methoxy-1,2,3,4-tetrahydro- $\beta$-carboline in pineal gland of chicken and cock. FEBS Lett 1981; 127: 277-80.

[37] Leino M, Kari I, Airaksinen MM, Gynther J. 6-Methoxytetrahydro- $\beta$-carboline in the retinae of rabbits and pigs. Exp Eye Res 1983; 36: 135-8.

[38] Tan D-X, Chen L-D, Poeggeler B, Manchester LC, Reiter RJ. Melatonin: a potent, endogenous hydroxyl radical scavenger. Endocr J 1993; 1: 57-60.

[39] Poeggeler B, Reiter RJ, Hardeland R, Tan D-X, Barlow-Walden LR. Melatonin and structurally-related, endogenous indoles act as potent electron donors and radical scavengers in vitro. Redox Rep 1996; 2: 179-84.

[40] Tan D-X, Reiter RJ, Manchester LC, et al. Chemical and physical properties and potential mechanisms: melatonin as a broad spectrum antioxidant and free radical scavenger. Curr Top Med Chem 2002; 2: 181-97.

[41] Köhidai L, Vakkuri O, Keresztesi M, Leppäluoto J, Csaba G. Induction of melatonin synthesis in Tetrahymena pyriformis by hormonal imprinting - a unicellular "factory" of the indoleamine. Cell Mol Biol 2003; 49: 521-4.

[42] Thomas JN, Smith-Sonneborn J. Supplemental melatonin increases clonal lifespan in the protozoan Paramecium tetraurelia. J Pineal Res 1997; 23: 123-30. 
[43] Banerjee S, Kerr V, Winston M, Kelleher JK, Margulis L. Melatonin: inhibition of microtubule-based oral morphogenesis in Stentor coeruleus. J Protozool 1972; 19: 108-13.

[44] Hardeland, R. New actions of melatonin and their relevance to biometeorology. Int J Biometeorol 1997; 41: 47-57.

[45] Balzer I, Robertson DL, Hastings JW. Melatonin does not shift the circadian phase of Gonyaulax polyedra. International Congress on Chronobiology, 1999 Aug 28 - Sep 1; Washington, DC, p. 47.

[46] Antolín I, Obst B, Burkhardt S, Hardeland R. Antioxidative protection in a high-melatonin organism: The dinoflagellate Gonyaulax polyedra is rescued from lethal oxidative stress by strongly elevated, but physiologically possible concentrations of melatonin. J Pineal Res 1997; 23: 182-90.

[47] Reiter RJ, Tan D-X, Mayo JC, Sainz RM, Leon J, Czarnocki Z. Melatonin as an antioxidant: biochemical mechanisms and pathophysiological implications in humans. Acta Biochim Pol 2003; 50: 1129-46.

[48] Rodriguez C, Mayo JC, Sainz RM, et al. Regulation of antioxidant enzymes: a significant role for melatonin. J Pineal Res 2004; 36 : 1 9.

[49] Hardeland R. Antioxidative protection by melatonin: multiplicity of mechanisms from radical detoxification to radical avoidance. Endocrine 2005; 27: 119-30.

[50] Hardeland R, Fuhrberg B. In: Hardeland R, Ed. Time course of aryl acylamidase activity in Gonyaulax polyedra under cyst-inducing conditions. In: Metabolism and Cellular Dynamics of Indoles. University of Göttingen, Göttingen, 1996; 70-3

[51] Balzer I, Hardeland R. Stimulation of bioluminescence by 5methoxylated indoleamines in the dinoflagellate, Gonyaulax polyedra. Comp Biochem Physiol 1991; 98C: 395-7.

[52] Balzer I, Hardeland R. Circadian rhythmicity in the stimulation of bioluminescence by biogenic amines and MAO inhibitors in Gonyaulax polyedra. Int J Biometeorol 1991; 34: 231-4.

[53] Burkhardt S, Hardeland R. Circadian rhythmicity of tryptophan hydroxylase in the marine dinoflagellate Gonyaulax polyedra Stein and the role of tryptophan hydroxylation in bioluminescence. Comp Biochem Physiol 1996; 115B: 411-6.

[54] Hardeland R, Burkhardt S. In: Hardeland R, Ed. On the restoration of the Gonyaulax glow peak following suppression of indoleamine biosynthesis by inhibitors of tryptophan hydroxylase: An update. In: Biological Rhythms and Antioxidative Protection. Cuvillier, Göttingen, 1997; 78-85.

[55] Burkhardt S, Meyer TJ, Hardeland R, Poeggeler B, Fuhrberg B, Balzer I. Requirement of indoleamines and a V-type proton ATPase for the expression of the circadian glow rhythm in Gonyaulax polyedra. Biol Rhythm Res 1997; 28: 151-9.

[56] Burkhardt S, Meyer TJ, Hardeland R, Fuhrberg B. Significance of indoleamines and a V-type proton ATPase in the circadian glow rhythm of Gonyaulax polyedra (Dinoflagellata). Biometeorology 1997; 14 (Pt 2/2): 266-71.

[57] Burkhardt S, Antolín I, Hardeland R, Fuhrberg B, Poeggeler B. 5Methoxytryptamine is required for the Gonyaulax glow maximum. J Biolum Chemilum 1998; 13: 204

[58] Balzer I, Hardeland R. Photoperiodism and effects of indoleamines in a unicellular alga, Gonyaulax polyedra. Science 1991; 253: 7957 .

[59] Balzer I, Hardeland R. Effects of indoleamines and short photoperiods on the encystment of Gonyaulax polyedra. Chronobiol Int 1992; 9: 260-5.

[60] Balzer I, Hardeland R. In: Gutenbrunner C, Hildebrandt G, Moog $\mathrm{R}$, Eds. On the mechanism of cyst induction in Gonyaulax polyedra: Roles of photoperiodism, low temperature, 5-methoxylated indoleamines, and proton release. In: Chronobiology \& Chronomedicine. Lang, Frankfurt/M, 1993; 127-33.

[61] Hardeland R, Fuhrberg B, Wolf R. In: Hardeland R, Ed. Rapid and slow processes in the encystment response of Gonyaulax polyedra. In: Metabolism and Cellular Dynamics of Indoles. University of Göttingen, Göttingen, 1996; 94-9.

[62] Hardeland R. In: Hardeland R, Ed. Indoleamine-induced encystment in dinoflagellates: On the problems of distinguishing between proton and calcium effects. In: Studies on Antioxidants and Their Metabolites. Cuvillier, Göttingen, 1999; 184-90.

[63] Van Tassel DL, O'Neill SD. Putative regulatory molecules in plants: evaluating melatonin. J Pineal Res 2001; 31: 1-7.

[64] Kolář J, Macháčková I. Melatonin in higher plants: occurrence and possible functions. J Pineal Res 2005; 39: 333-41.
[65] Koláŕ J, Macháčková I, Eder J, et al. Melatonin: occurrence and daily rhythm in Chenopodium rubrum. Phytochemistry 1997; 44: 1407-13

[66] van Tassel DL, Roberts N, Lewy A, O’Neill SD. Melatonin in plant organs. J Pineal Res 2001; 31: 8-15.

[67] Tan D-X, Manchester LC, Di Mascio P, Martinez GR, Prado FM, Reiter RJ. Novel rhythms of $N^{1}$-acetyl- $N^{2}$-formyl-5-methoxykynuramine and its precursor melatonin in water hyacinth: importance for phytoremediation. FASEB J 2007; 21: 1724-9.

[68] Hernández-Ruiz J, Cano A, Arnao MB. Melatonin: a growthstimulating compound present in lupin tissues. Planta 2004; 220: 140-4.

[69] Hernández-Ruiz J, Cano A, Arnao MB. Melatonin acts as a growth-stimulating compound in some monocot species. J Pineal Res 2005; 39: 137-42.

[70] Balzer I, Hardeland R. Melatonin in algae and higher plants - Possible new roles as a phytohormone and antioxidant. Bot Acta 1996; 109: 180-3.

[71] Behrmann G, Fuhrberg B, Hardeland R, Uría H, Poeggeler B. Photooxidation of melatonin, 5-methoxytryptamine and 5methoxytryptophol: aspects of photoprotection by periodically fluctuating molecules? Biometeorology 1997; 14 (Pt 2/2): 258-63.

[72] Tosini G, Menaker M. Multioscillatory circadian organization in a vertebrate, Iguana iguana. J Neurosci 1998; 18: 1105-14.

[73] Cardinali DP, Nagle CA, Rosner JM. Periodic changes in rat retinal and pineal melatonin synthesis. Acta Physiol Lat Am 1974; 24: 978.

[74] Gern WA, Ralph CL. Melatonin synthesis by the retina. Science 1979; 204: 183-4.

[75] Vivien-Roels B, Pévet P, Dubois MP, Arendt J, Brown GM. Immunohistochemical evidence for the presence of melatonin in the pineal gland, the retina and the Harderian gland. Cell Tissue Res 1981; 217: 105-15

[76] Besharse JC, Iuvone PM. Circadian clock in Xenopus eye controlling retinal serotonin $N$-acetyltransferase. Nature 1983; 305: 133-5.

[77] Dubocovich ML. Melatonin is a potent modulator of dopamine release in the retina. Nature 1983; 306: 782-4.

[78] Wiechmann AF. Melatonin: parallels in pineal gland and retina Exp Eye Res 1986; 42: 507-27.

[79] Cahill GM, Besharse JC. Retinal melatonin is metabolized within the eye of Xenopus laevis. Proc Natl Acad Sci USA 1989; 86: 1098-102.

[80] Nowak JZ, Kazula A, Golembiowska K. Melatonin increases serotonin $\mathrm{N}$-acetyltransferase activity and decreases dopamine synthesis in light-exposed chick retina: in vivo evidence supporting melatonin-dopamine interaction in retina. J Neurochem 1992; 59: 1499505 .

[81] Kazula A, Nowak JZ, Iuvone PM. Regulation of melatonin and dopamine biosynthesis in chick retina: the role of GABA. Vis Neurosci 1993; 10: 621-9.

[82] Green CB. Molecular control of Xenopus retinal circadian rhythms. J Neuroendocrinol 2003; 15: 350-4.

[83] Tosini G, Fukuhara C. Photic and circadian regulation of retinal melatonin in mammals. J Neuroendocrinol 2003; 15: 364-9.

[84] Lundmark PO, Pandi-Perumal SR, Srinivasan V, Cardinali DP. Role of melatonin in the eye and ocular dysfunctions. Vis Neurosci 2006; 23: 853-62.

[85] Zeman M, Józsa R, Cornélissen G, et al. Chronomics: Circadian lead of extrapineal vs. pineal melatonin rhythms with an infradian hypothalamic exploration. Biomed Pharmacother 2005; 59: S213-9.

[86] Jozsa R, Halberg F, Cornélissen G, et al. Chronomics, neuroendocrine feedsidewards and the recording and consulting of nowcastsforecasts of geomagnetics. Biomed Pharmacother 2005; 59: S2430 .

[87] Kazula A, Nowak JZ. The role of GABA-ergic signal in the regulation of melatonin biosynthesis in vertebrate retina. Pol J Pharmacol Pharm 1992; 44: 611-25.

[88] Zawilska JB, Derbiszewska T, Nowak JZ. Clozapine and other neuroleptic drugs antagonize the light-evoked suppression of melatonin biosynthesis in chick retina: involvement of the D4-like dopamine receptor. J Neural Transm Gen Sect 1994; 97: 107-17.

[89] Zawilska JB, Nowak JZ. Does D4 dopamine receptor mediate the inhibitory effect of light on melatonin biosynthesis in chick retina? Neurosci Lett 1994; 166: 203-6.

[90] Zawilska JB, Berezinska M, Rosiak J, Skene DJ, Vivien-Roels B, Nowak JZ. Suppression of melatonin biosynthesis in the chicken 
pineal gland by retinally perceived light - involvement of D1dopamine receptors. J Pineal Res 2004; 36: 80-6.

[91] Grace MS, Cahill GM, Besharse JC. Melatonin deacetylation: retinal vertebrate class distribution and Xenopus laevis tissue distribution. Brain Res 1991; 559: 56-63.

[92] Grace MS, Besharse JC. Solubilization and biochemical characterization of the melatonin deacetylase from Xenopus laevis retina. J Neurochem 1993; 60: 990-9.

[93] Li P, Pang SF, Tsang CW. Retinal 5-methoxytryptamine and 5methoxyindole-3-acetic acid in the rat and quail: diurnal rhythms and interspecies differences. Biochem Biophys Res Commun 1997; 239: 353-6.

[94] Iuvone PM, Gan J, Alonso-Gómez AL. 5-Methoxytryptamine inhibits cyclic AMP accumulation in cultured retinal neurons through activation of a pertussis toxin-sensitive site distinct from the $2-\left[{ }^{125} I\right]$ iodomelatonin binding site. J Neurochem 1995; 64: $1892-5$.

[95] Matsubara E, Bryant-Thomas T, Pacheco Quinto J, et al. Melatonin increases survival and inhibits oxidative and amyloid pathology in a transgenic model of Alzheimer's disease. J Neurochem 2003; 85: $1101-8$.

[96] Tricoire H, Locatelli A, Chemineau P, Malpaux B. Melatonin enters the cerebrospinal fluid through the pineal recess. Endocrinology 2002; 143: 84-90.

[97] Tricoire H, Malpaux B, Møller M. Cellular lining of the sheep pineal recess studied by light, transmission, and scanning electron microscopy: morphologic indications for a direct secretion of melatonin from the pineal gland to the cerebrospinal fluid. J Comp Neurol 2003; 456: 39-47.

[98] Biesalski HK, Welker HA, Thalmann R, Vollrath L. Melatonin and other serotonin derivatives in the guinea pig membranous cochlea. Neurosci Lett 1988; 91: 41-6.

[99] Hoffman RA, Johnson LB, Reiter RJ. Harderian glands of golden hamsters: temporal and sexual differences in immunoreactive melatonin. J Pineal Res 1985; 2: 161-8.

[100] Menendez-Pelaez A, Reiter RJ, Gonzalez-Brito A, Howes KA. Nacetyltransferase activity and indole contents of the male Syrian hamster Harderian gland: changes during the light dark cycle. Arch Biochem Biophys 1989; 268: 20-5.

[101] Menéndez-Peláez A. Melatonin and other indoles in the rodent Harderian glands: regulation and physiological significance. Adv Pineal Res 1990; 4: 75-80.

[102] Menendez-Pelaez A, Buzzell GR, Rodriguez C, Reiter RJ. Indole and porphyrin content of the Syrian hamster harderian glands during the proestrous and estrous phases of the estrous cycle. J Steroid Biochem Mol Biol 1991; 38: 101-4.

[103] Buzzell GR, Pangerl A, Pangerl B, et al. Melatonin and porphyrin in the harderian glands of the Syrian hamster: circadian patterns and response to autumnal conditions. Int J Biochem 1990; 22: $1465-9$.

[104] Marrufo B, Menendez-Pelaez A, Buzzell GR, Gonzalez-Brito A, Reiter RJ. 5 alpha-dihydrotestosterone administration converts indoleamine metabolism and porphyrin content of the female Syrian hamster Harderian gland to the male type. Proc Soc Exp Biol Med 1989; 192: 192-5.

[105] Menendez-Pelaez A, Rodriguez C, Dominguez P. 5aminolevulinate synthase mRNA levels in the Harderian gland of Syrian hamsters: correlation with porphyrin concentrations and regulation by androgens and melatonin. Mol Cell Endocrinol 1991; 80: $177-82$.

[106] Buzzell GR, Menendez-Pelaez A, Chlumecky V, Reiter RJ. Gender differences and time course of castration-induced changes in porphyrins, indoles, and proteins in the Harderian glands of the Syrian hamster. Can J Physiol Pharmacol 1991; 69: 1814-8.

[107] Stankov B, Lucini V, Negri-Cesi P, Cozzi B, Fumagalli P, Fraschini $\mathrm{F}$. Regulation of the androgen receptors in the harderian gland of the male Syrian hamster: influence of photoperiod, castration, and chronic melatonin treatment. J Pineal Res 1992; 13: 20-7.

[108] Huether G. The contribution of extrapineal sites of melatonin synthesis to circulating melatonin levels in higher vertebrates. Experientia 1993; 49: 665-70.

[109] Huether G. Melatonin synthesis in the gastrointestinal tract and the impact of nutritional factors on circulating melatonin. Ann NY Acad Sci 1994; 719: 146-58.
[110] Bubenik GA. Localization, physiological significance and possible clinical implication of gastrointestinal melatonin. Biol Signals Recept 2001; 10: 350-66.

[111] Bubenik GA. Gastrointestinal melatonin: localization, function, and clinical relevance. Dig Dis Sci 2002; 47: 2336-48.

[112] Kvetnoy IM, Ingel IE, Kvetnaia TV, et al. Gastrointestinal melatonin: cellular identification and biological role. Neuroendocrinol Lett 2002; 23: 121-32.

[113] Konturek SJ, Konturek PC, Brzozowska I, et al. Localization and biological activities of melatonin in intact and diseased gastrointestinal tract (GIT). J Physiol Pharmacol 2007; 58: 381-405.

[114] Messner M, Hardeland R, Rodenbeck A, Huether G. Tissue retention and subcellular distribution of continuously infused melatonin in rats under near physiological conditions. J Pineal Res 1998; 25: 251-9.

[115] Messner M, Hardeland R, Rodenbeck A, Huether G. Effects of continuous melatonin infusions on steady-state plasma melatonin levels, metabolic fate and tissue retention in rats under near physiological conditions. Adv Exp Med Biol 1999; 467: 303-13.

[116] Tan D-X, Manchester LC, Reiter RJ, Qi W, Hanes MA, Farley NJ. High physiological levels of melatonin in the bile of mammals. Life Sci 1999; 65: 2523-9.

[117] Bubenik GA, Hacker RR, Brown GM, Bartos L. Melatonin concentrations in the luminal fluid, mucosa and muscularis of the bovine and porcine gastrointestinal tract. J Pineal Res 1999; 26: 56-63.

[118] Hattori A, Migitaka H, Iigo M, et al. Identification of melatonin in plants and its effects on plasma melatonin levels and binding to melatonin receptors in vertebrates. Biochem Mol Biol Int 1995; 35: 627-34

[119] Tan D-X, Manchester LC, Hardeland R, et al. Melatonin - a hormone, a tissue factor, an autocoid, a paracoid, and an antioxidant vitamin. J Pineal Res 2003; 34: 75-8.

[120] Stebelova K, Zeman M, Cornélissen G, et al. Chronomics reveal and quantify circadian rhythmic melatonin in duodenum of rats. Biomed Pharmacother 2005; 59: S209-12.

[121] Poeggeler B, Cornélissen G, Huether G, et al. Chronomics affirm extending scope of lead in phase of duodenal vs pineal circadian melatonin rhythms. Biomed Pharmacother 2005; 59: S220-4.

[122] Huether G, Poeggeler B, Reimer A, George A. Effect of tryptophan administration on circulating melatonin levels in chicks and rats: evidence for stimulation of melatonin synthesis and release in the gastrointestinal tract. Life Sci 1992; 51: 945-53.

[123] Gaudet SJ, Slominski A, Etminan M, Pruski D, Paus R, Namboodiri MA. Identification and characterization of two isozymic forms of arylamine N-acetyltransferase in Syrian hamster skin. J Invest Dermatol 1993; 101: 660-5.

[124] Slominski A, Pisarchik A, Semak I, et al. Serotoninergic and melatoninergic systems are fully expressed in human skin. FASEB J 2002; 16: 896-8.

[125] Semak I, Korik E, Naumova M, Wortsman J, Slominski A. Serotonin metabolism in rat skin: characterization by liquid chromatography-mass spectrometry. Arch Biochem Biophys 2004; 421: 61-6.

[126] Slominski A, Wortsman J, Tobin DJ. The cutaneous serotoninergic/melatoninergic system: securing a place under the sun. FASEB J 2005; 19; 176-94.

[127] Slominski A, Fischer TW, Zmijewski MA, et al. On the role of melatonin in skin physiology and pathology. Endocrine 2005; 27: $137-48$.

[128] Slominski A, Tobin DJ, Zmijewski MA, Wortsman J, Paus R. Melatonin in the skin: synthesis, metabolism and functions. Trends Endocrinol Metab 2008; 19: 17-24.

[129] Slominski A, Pisarchik A, Semak I, Sweatman T, Wortsman J. Characterization of the serotoninergic system in the $\mathrm{C} 57 \mathrm{BL} / 6$ mouse skin. Eur J Biochem 2003; 270: 3335-44.

[130] Fischer TW, Sweatman TW, Semak I, Sayre RM, Wortsman J, Slominski A. Constitutive and UV-induced metabolism of melatonin in keratinocytes and cell-free systems. FASEB J 2006; 20: 1564-6. Erratum in: FASEB J 2007; 21: 630.

[131] Fischer TW, Zbytek B, Sayre RM, et al. Melatonin increases survival of HaCaT keratinocytes by suppressing UV-induced apoptosis. J Pineal Res 2006; 40: 18-26.

[132] Fischer TW, Zmijewski MA, Wortsman J, Slominski A. Melatonin maintains mitochondrial membrane potential and attenuates activation of initiator (casp-9) and effector caspases (casp-3/casp-7) and PARP in UVR-exposed HaCaT keratinocytes. J Pineal Res 2007 Dec 13; [Epub ahead of print]. 
[133] Fischer TW, Zmijewski MA, Zbytek B, et al. Oncostatic effects of the indole melatonin and expression of its cytosolic and nuclear receptors in cultured human melanoma cell lines. Int J Oncol 2006; 29: 665-72.

[134] Itoh MT, Ishizuka B, Kuribayashi Y, Amemiya A, Sumi Y. Melatonin, its precursors, and synthesizing enzyme activities in the human ovary. Mol Hum Reprod 1999; 5: 402-8.

[135] Conti A, Conconi S, Hertens E, Skwarlo-Sonta K, Markowska M, Maestroni GJM. Evidence for melatonin synthesis in mouse and human bone marrow cells. J Pineal Res 2000; 28: 193-202.

[136] Maestroni GJM, Zammaretti F, Pedrinis E. Hematopoietic effect of melatonin involvement of type 1 kappa-opioid receptor on bone marrow macrophages and interleukin-1. J Pineal Res 1999; 27: 145-53.

[137] Finocchiaro LM, Arzt ES, Fernández-Castelo S, Criscuolo M, Finkielman S, Nahmod VE. Serotonin and melatonin synthesis in peripheral blood mononuclear cells: stimulation by interferon- $\gamma$ as part of an immunomodulatory pathway. J Interferon Res 1988; 8: 705-16.

[138] Finocchiaro LM, Nahmod VE, Launay JM. Melatonin biosynthesis and metabolism in peripheral blood mononuclear leucocytes. Biochem J 1991; 280: 727-31.

[139] Carrillo-Vico A, Calvo JR, Abreu P, et al. Evidence of melatonin synthesis by human lymphocytes and its physiological significance: possible role as intracrine, autocrine, and/or paracrine substance. FASEB J 2004; 18: 537-9.

[140] Carrillo-Vico A, Guerrero JM, Lardone PJ, Reiter RJ. A review of the multiple actions of melatonin on the immune system. Endocrine 2005; 27: 189-200.

[141] Launay JM, Lamaître BJ, Husson HP, Dreux C, Hartmann L, Da Prada M. Melatonin synthesis by rabbit platelets. Life Sci 1982; 31 : 1487-94.

[142] Rosengarten H, Meller E, Friedhoff AJ. In vitro enzymatic formation of melatonin by human erythrocytes. Res Commun Chem Pathol Pharmacol 1972; 4: 457-65.

[143] Mueller U, Hardeland R. In: Hardeland R. Ed. Transient accumulations of exogenous melatonin indicate binding sites in the dinoflagellate Gonyaulax polyedra. In: Studies on Antioxidants and Their Metabolites. Cuvillier, Göttingen, 1999; 140-7.

[144] Macías M, Escames G, Leon J, et al. Calreticulin - melatonin. An unexpected relationship. Eur J Biochem 2003; 270: 832-40.

[145] Menendez-Pelaez A, Poeggeler B, Reiter, RJ, Barlow-Walden L, Pablos MI, Tan D-X. Nuclear localization of melatonin in different mammalian tissues: immunocytochemical and radioimmunoassay evidence. J Cell Biochem 1993; 53: 373-82.

[146] Ebisawa T, Karne S, Lerner MR, Reppert SM. Expression cloning of a high-affinity melatonin receptor from Xenopus dermal melanophores. Proc Natl Acad Sci USA 1994; 91: 6133-7.

[147] Reppert SM, Weaver DR, Ebisawa T. Cloning and characterization of a mammalian melatonin receptor that mediates reproductive and circadian responses. Neuron 1994; 13: 1177-85.

[148] Slaugenhaupt SA, Roca AL, Liebert CB, Altherr MR, Gusella JF, Reppert SM. Mapping of the gene for the $\mathrm{Mel}_{1 \mathrm{a}}$-melatonin receptor to human chromosome $4(M T N R 1 A)$ and mouse chromosome 8 (Mtnrla). Genomics 1995; 27: 355-7.

[149] Reppert SM, Godson C, Mahle CD, Weaver DR, Slaugenhaupt SA, Gusella JF. Molecular characterization of a second melatonin receptor expressed in human retina and brain: the $\mathrm{Mel}_{\mathrm{lb}}$ melatonin receptor. Proc Natl Acad Sci USA 1995; 92: 8734-8.

[150] Liu C, Weaver DR, Jin X, et al. Molecular dissection of two distinct actions of melatonin on the suprachiasmatic circadian clock. Neuron 1997; 19: 91-102.

[151] Reppert SM. Melatonin receptors: molecular biology of a new family of $\mathrm{G}$ protein-coupled receptors. J Biol Rhythms 1997; 12: 528-31.

[152] Jin X, von Gall C, Pieschl RL, et al. Targeted disruption of the mouse $\mathrm{Mel}_{\mathrm{lb}}$ melatonin receptor. Mol Cell Biol 2003; 23: 1054-60.

[153] Dubocovich ML, Markowska M. Functional MT $\mathrm{M}_{1}$ and $\mathrm{MT}_{2}$ melatonin receptors in mammals. Endocrine 2005; 27: 101-10.

[154] García-Pergañeda A, Guerrero JM, Rafii-El-Idrissi M, Paz Romero M, Pozo D, Calvo JR. Characterization of membrane melatonin receptor in mouse peritoneal macrophages: inhibition of adenylyl cyclase by a pertussis toxin-sensitive $G$ protein. J Neuroimmunol 1999; 95: 85-94.

[155] Schuster C, Gauer F, Guerrero H, Lakhdar-Ghazal N, Pévet P, Masson-Pévet $\mathrm{M}$. Photic regulation of $\mathrm{mt} 1 \mathrm{melatonin}$ receptors in the Siberian hamster pars tuberalis and suprachiasmatic nuclei: involvement of the circadian clock and intergeniculate leaflet. J Neuroendocrinol 2000; 12: 207-16.

[156] Poirel VJ, Cailotto C, Streicher D, Pévet P, Masson-Pévet M, Gauer F. $\mathrm{MT}_{1}$ melatonin receptor mRNA tissular localization by PCR amplification. Neuroendocrinol Lett 2003; 24: 33-8

[157] Steffens F, Zhou X-B, Sausbier U, et al. Melatonin receptor signaling in pregnant and nonpregnant rat uterine myocytes as probed by large conductance $\mathrm{Ca}^{2+}$-activated $\mathrm{K}^{+}$channel activity. Mol Endocrinol 2003; 17: 2103-15.

[158] Carrillo-Vico A, García-Pergañeda A, Naji L, Calvo JR, Romero MP, Guerrero JM. Expression of membrane and nuclear melatonin receptor mRNA and protein in the mouse immune system. Cell Mol Life Sci 2003; 60: 2272-8.

[159] Ekmekcioglu C, Thalhammer T, Humpeler S, et al. The melatonin receptor subtype $\mathrm{MT}_{2}$ is present in the human cardiovascular system. J Pineal Res 2003; 35: 40-4.

[160] Díaz López B, Díaz Rodríguez E, Urquijo C, Fernández Alvarez C. Melatonin influences on the neuroendocrine-reproductive axis. Ann NY Acad Sci 2005; 1057: 337-64.

[161] Wu Y-H, Zhou J-N, Balesar R, et al. Distribution of MT1 melatonin receptor immunoreactivity in the human hypothalamus and pituitary gland: colocalization of MT1 with vasopressin, oxytocin, and corticotropin-releasing hormone. J Comp Neurol 2006; 499: 897-910.

[162] Hunt AE, Al-Ghoul WM, Gillette MU, Dubocovich ML. Activation of $\mathrm{MT}_{2}$ melatonin receptors in rat suprachiasmatic nucleus phase advances the circadian clock. Am J Physiol 2001, 280: C1108.

[163] Pévet P, Bothorel B, Slotten H, Saboureau M. The chronobiotic properties of melatonin. Cell Tissue Res 2002; 309: 183-91.

[164] Dubocovich ML, Rivera-Bermudez MA, Gerdin MJ, Masana MI. Molecular pharmacology, regulation and function of mammalian melatonin receptors. Front Biosci 2003; 8: d1093-108.

[165] Weaver DR, Liu C, Reppert SM. Nature's knockout: the Mel $_{1 b}$ receptor is not necessary for reproductive and circadian responses to melatonin in Siberian hamsters. Mol Endocrinol 1996; 10: 147887.

[166] Vane ek J. Cellular mechanisms of melatonin action. Physiol Rev 1998; 78: 687-721

[167] Roka F, Brydon L, Waldhoer M, et al. Tight association of the human $\mathrm{Mel}_{1 \mathrm{a}}$-melatonin receptor and $\mathrm{G}_{\mathrm{i}}$ : precoupling and constitutive activity. Mol Pharmacol 1999; 56: 1014-24

[168] Brydon L, Roka F, Petit L, et al. Dual signaling of human $\mathrm{Mel}_{\mathrm{la}}$ melatonin receptors via $\mathrm{G}_{\mathrm{i} 2}, \mathrm{G}_{\mathrm{i} 3}$, and $\mathrm{G}_{\mathrm{q} / 11}$ proteins. Mol Endocrinol 1999; 13: 2025-38.

[169] Roy D, Belsham DD. Melatonin receptor activation regulates GnRH gene expression and secretion in GT1-7 GnRH neurons. Signal transduction mechanisms. J Biol Chem 2002; 277: 251-8.

[170] Chan AS, Lai FP, Lo RK, Voyno-Yasenetskaya TA, Stanbridge EJ, Wong YH. Melatonin mt1 and MT2 receptors stimulate c-Jun Nterminal kinase via pertussis toxin-sensitive and -insensitive $\mathrm{G}$ proteins. Cell Signal 2002; 14: 249-57.

[171] Lai FP, Mody SM, Yung LY, Kam JY, Pang CS, Pang SF, Wong $\mathrm{YH}$. Molecular determinants for the differential coupling of $\mathrm{G}_{16}$ to the melatonin $\mathrm{MT}_{1}, \mathrm{MT}_{2}$ and Xenopus $\mathrm{Mel}_{\mathrm{lc}}$ receptors. J Neurochem 2002; 80: 736-45.

[172] Yung LY, Tsim ST, Wong YH. Stimulation of cAMP accumulation by the cloned Xenopus melatonin receptor through $\mathrm{G}_{\mathrm{i}}$ and $\mathrm{G}_{\mathrm{z}}$ proteins. FEBS Lett 1995; 372; 99-102.

[173] McArthur AJ, Hunt EA, Gillette MU. Melatonin action and signal transduction in the rat suprachiasmatic circadian clock: Activation of protein kinase C at dusk and dawn. Endocrinology 1997; 138: 627-34.

[174] Godson C, Reppert SM. The $\mathrm{Mel}_{\mathrm{la}}$ melatonin receptor is coupled to parallel signal transduction pathways. Endocrinology 1997; 138: 397-404.

[175] García-Pergañeda A, Pozo D, Guerrero JM, Calvo JR. Signal transduction for melatonin in human lymphocytes: involvement of a pertussis toxin-sensitive G protein. J Immunol 1997; 159: 377481.

[176] von Gall C, Stehle JH, Weaver DR. Mammalian melatonin receptors: molecular biology and signal transduction. Cell Tissue Res 2002; 309: 151-62. 
[177] Sharkey J, Olcese J. Transcriptional inhibition of oxytocin receptor expression in human myometrial cells by melatonin involves protein kinase C signaling. J Clin Endocrinol Metab 2007; 92: 4015-9.

[178] Mahle CD, Goggins GD, Agarwal P, Ryan E, Watson AJ. Melatonin modulates vascular smooth muscle tone. J Biol Rhythms 1997; 12: 690-6.

[179] Doolen S, Krause DN, Dubocovich ML, Duckles SP. Melatonin mediates two distinct responses in vascular smooth muscle. Eur J Pharmacol 1998; 345: 67-9.

[180] Régrigny O, Delagrange P, Scalbert E, Atkinson J, LartaudIdjouadiene I. Melatonin improves cerebral circulation security margin in rats. Am J Physiol 1998; 275: H139-44.

[181] Hardeland R, Poeggeler B, Srinivasan V, Trakht I, Pandi-Perumal SR, Cardinali DP. Melatonergic drugs in clinical practice. Arzneimittelforschung 2008; 58: 1-10.

[182] Nosjean O, Ferro M, Cogé F, et al. Identification of the melatoninbinding site MT3 as the quinone reductase 2. J Biol Chem 2000; 275: 31311-7.

[183] Nosjean O, Nicolas JP, Klupsch F, Delagrange P, Canet E, Boutin JA. Comparative parmacological studies of melatonin receptors: MT1, MT2 and MT3/QR2. Tissue distribution of MT3/QR2. Biochem Pharmacol 2001; 61: 1369-79.

[184] Witt-Enderby PA, Bennett J, Jarzynska MJ, Firestine S, Melan MA. Melatonin receptors and their regulation: biochemical and structural mechanisms. Life Sci 2003; 72: 2183-98.

[185] Mailliet F, Ferry G, Vella F, Thiam K, Delagrange P. Boutin JA. Organs from mice deleted for NRH:quinone oxidoreductase 2 are deprived of the melatonin binding site MT3. FEBS Lett 2004; 578: 116-20.

[186] Vella F, Ferry G, Delagrange P, Boutin JA. NRH:quinone reductase 2: an enzyme of surprises and mysteries. Biochem Pharmacol 2005; 71: 1-12.

[187] Mailliet F, Ferry G, Vella F, et al. Characterization of the melatoninergic $\mathrm{MT}_{3}$ binding site on the NRH:quinone oxidoreductase 2 enzyme. Biochem Pharmacol 2005; 71: 74-8.

[188] Boussard MF, Truche S, Rousseau-Rojas A, et al. New ligands at the melatonin binding site $\mathrm{MT}_{3}$. Eur J Med Chem 2006; 41: 306-20.

[189] Jaiswal AK. Human NAD(P)H:quinone oxidoreductase2. Gene structure, activity, and tissue-specific expression. J Biol Chem 1994; 269: 14502-8

[190] Long DJ II, Jaiswal AK. Mouse NRH:quinone oxidoreductase (NQO2): cloning of cDNA and gene- and tissue-specific expression. Gene 2000; 252: 107-17.

[191] Harada S, Fujii C, Hayashi A, Ohkoshi N. An association between idiopathic Parkinson's disease and polymorphisms of phase II detoxification enzymes: glutathione S-transferase M1 and quinone oxidoreductase 1 and 2. Biochem Biophys Res Commun 2001; 288: 887-92.

[192] Long DJ II, Iskander K, Gaikwad A, et al. Disruption of dihydronicotinamide riboside:quinone oxidoreductase 2 (NQO2) leads to myeloid hyperplasia of bone marrow and decreased sensitivity to menadione toxicity. J Biol Chem 2002; 277: 46131-9.

[193] Tan D-X, Manchester LC, Terron MP, Flores LJ, Tamura H, Reiter RJ. Melatonin as a naturally occurring co-substrate of quinone reductase-2, the putative $\mathrm{MT}_{3}$ melatonin membrane receptor: hypothesis and significance. J Pineal Res 2007; 43: 317-20.

[194] Benítez-King G, Huerto-Delgadillo L, Antón-Tay F. Binding of ${ }^{3} \mathrm{H}-$ melatonin to calmodulin. Life Sci 1993; 53: 201-7.

[195] Benítez-King G, Antón-Tay F. Calmodulin mediates melatonin cytoskeletal effects. Experientia 1993; 49: 635-41.

[196] Benítez-King G, Ríos A, Martínez A, Antón-Tay F. In vitro inhibition of $\mathrm{Ca}^{2+} /$ calmodulin-dependent kinase II activity by melatonin. Biochim Biophys Acta 1996; 1290: 191-6.

[197] Benítez-King G. Melatonin as a cytoskeletal modulator: implications for cell physiology and disease. J Pineal Res 2006; 40: 1-9.

[198] Srinivasan V, Pandi-Perumal SR, Cardinali DP, Poeggeler B, Hardeland R. Melatonin in Alzheimer's disease and other neurodegenerative disorders. Behav Brain Funct 2006 May 4. 2: article no. 15 [23 screens]. Available from: $\mathrm{http}: / / \mathrm{www}$.behavioralandbrainfunctions.com/content/2/1/15.

[199] León J, Macías M, Escames G, et al. Structure-related inhibition of calmodulin-dependent neuronal nitric-oxide synthase activity by melatonin and synthetic kynurenines. Mol Pharmacol 2000; 58: 967-75.
[200] Soto-Vega E, Meza I, Ramírez-Rodríguez G, Benitez-King G. Melatonin stimulates calmodulin phosphorylation by protein kinase C. J Pineal Res 2004; 37: 98-106.

[201] Wiesenberg I, Missbach M, Kahlen JP, Schräder M, Carlberg C. Transcriptional activation of the nuclear receptor RZR $\alpha$ by the pineal gland hormone melatonin and identification of CGP 52608 as a synthetic ligand. Nucleic Acids Res 1995; 23: 327-33.

[202] Carlberg C. Gene regulation by melatonin. Ann NY Acad Sci 2000; 917: 387-96.

[203] Tomás-Zapico C, Boga JA, Caballero B, et al. Coexpression of MT1 and ROR $\alpha 1$ melatonin receptors in the Syrian hamster Harderian gland. J Pineal Res 2005; 39: 21-6.

[204] Tomás-Zapico C, Coto-Montes A. A proposed mechanism to explain the stimulatory effect of melatonin on antioxidative enzymes. J Pineal Res 2005; 39: 99-104

[205] Andrabi SA, Sayeed I, Siemen D, Wolf G, Horn TF. Direct inhibition of the mitochondrial permeability transition pore: a possible mechanism responsible for anti-apoptotic effects of melatonin. FASEB J 2004; 18: 869-71.

[206] Morton DJ. Both hydroxy- and methoxyindoles modify basal temperature in the rat. J Pineal Res 1987; 4: 1-5.

[207] Langer SZ, Lee CR, Segonzac A, et al. Possible endocrine role of the pineal gland for 6-methoxytetrahydro- $\beta$-carboline, a putative endogenous neuromodulator of the $\left[{ }^{3} \mathrm{H}\right]$ imipramine recognition site. Eur J Pharmacol 1984; 102: 379-80.

[208] Airaksinen MM, Callaway JC, Nykvist P, Rägo L, Kari E, Gynther J. In: Touitou Y, Arendt J, Pévet P, Eds. Binding sites for $\left[{ }^{3} \mathrm{H}\right]$ pinoline. In: Melatonin and the Pineal Gland - From Basic Science to Clinical Application. Excerpta Medica, Amsterdam, 1993; 83-6.

[209] Marcusson JO, Bäckström IT, Ross SB. Single-site model of the neuronal 5-hydroxytryptamine uptake and imipramine-binding site. Mol Pharmacol 1986; 30: 121-8.

[210] Pähkla R, Rägo L, Callaway JJ, Airaksinen MM. Binding of pinoline on the 5-hydroxytryptamine transporter: competitive interaction with $\left[{ }^{3} \mathrm{H}\right]$ citalopram. Pharmacol Toxicol 1997; 80: 122-6.

[211] Sparks DL, Buckholtz NS. Combined inhibition of serotonin uptake and oxidative deamination attenuates audiogenic seizures in DBA/2J mice. Pharmacol Biochem Behav 1985; 23: 753-7.

[212] Sparks DL, Buckholtz NS. 6-Methoxy-1,2,3,4-tetrahydro- $\beta$ carboline: a specific monoamine oxidase-A inhibitor in $\mathrm{CF}-1$ mouse brain. Neurosci Lett 1980; 20: 73-8.

[213] Tan D-X, Manchester LC, Reiter RJ, et al. A novel melatonin metabolite, cyclic 3-hydroxymelatonin: a biomarker of in vivo hydroxyl radical generation. Biochem Biophys Res Commun 1998; 253: 614-20

[214] Tan D-X, Manchester LC, Reiter RJ, Plummer BF. Cyclic 3hydroxymelatonin: a melatonin metabolite generated as a result of hydroxyl radical scavenging. Biol Signals Recept 1999; 8: 70-4.

[215] Tan D-X, Hardeland R, Manchester LC, et al. Mechanistic and comparative studies of melatonin and classic antioxidants in terms of their interactions with the ABTS cation radical. J Pineal Res 2003; 34: 249-59.

[216] Ma X, Idle JR, Krausz KW, Tan D-X, Ceraulo L, Gonzalez FJ. Urinary metabolites and antioxidant products of exogenous melatonin in the mouse. J Pineal Res 2006; 40: 343-9.

[217] Tan D-X, Manchester LC, Burkhardt S, et al. $N^{1}$-acetyl- $N^{2}$-formyl5-methoxykynuramine, a biogenic amine and melatonin metabolite, functions as a potent antioxidant. FASEB J 2001; 15: 2294-6.

[218] Hardeland R, Ressmeyer A-R, Zelosko V, Burkhardt S, Poeggeler B. In: Haldar C, Singh SS, Eds. Metabolites of melatonin: Formation and properties of the methoxylated kynuramines AFMK and AMK. In: Recent Advances in Endocrinology and Reproduction: Evolutionary, Biotechnological and Clinical Applications. Banaras Hindu University, Varanasi, 2004; 21-38.

[219] Hardeland R, Poeggeler B, Niebergall R, Zelosko V. Oxidation of melatonin by carbonate radicals and chemiluminescence emitted during pyrrole ring cleavage. J Pineal Res 2003; 34: 17-25.

[220] Harthé C, Claudy D, Déchaud H, Vivien-Roels B, Pévet P, Claustrat B. Radioimmunoassay of $\mathrm{N}$-acetyl-N-formyl-5-methoxykynuramine (AFMK): a melatonin oxidative metabolite. Life Sci 2003; 73: 1587-97

[221] Rozov SV, Filatova EV, Orlov AA, et al. $N^{1}$-acetyl- $N^{2}$-formyl-5methoxy-kynuramine is a product of melatonin oxidation in rats. $\mathrm{J}$ Pineal Res 2003, 35: 245-50. 
[222] Hirata F, Hayaishi O, Tokuyama O, Senoh S. In vitro and in vivo formation of two new metabolites of melatonin. J Biol Chem 1974; 249: 1311-3.

[223] Ferry G, Ubeaud C, Lambert PH, et al. Molecular evidence that melatonin is enzymatically oxidized in a different manner than tryptophan. Investigation on both indoleamine-2,3-dioxygenase and myeloperoxidase. Biochem J 2005; 388: 205-15.

[224] Iwasaki Y, Kato Y, Ohgo S, et al. Effects of indoleamines and their newly identified metabolites on prolactin release in rats. Endocrinology 1978; 103: 254-8.

[225] Kennaway DJ, Hugel HM, Clarke S, et al. Structure-activity studies of melatonin analogues in prepubertal male rats. Aust J Biol Sci 1988; 41: 393-400.

[226] Marangos PJ, Patel J, Hirata F, et al. Inhibition of diazepam binding by tryptophan derivatives including melatonin and its brain metabolite N-acetyl-5-methoxykynurenamine. Life Sci 1981; 29: 25967.

[227] Kennaway DJ, Royles P, Webb H, Carbone F. Effects of protein restriction, melatonin administration, and short daylength on brain benzodiazepine receptors in prepubertal male rats. J Pineal Res 1988; 5: 455-67.

[228] Kennaway DJ, Hugel HM. Mechanims of action of melatonin within the central nervous system. Anim Reprod Sci 1992; 30: 4565 .

[229] Kennaway DJ, Hugel HM. Melatonin binding sites: are they receptors? Mol Cell Endocrinol 1992; 88: C1-9.

[230] Kennaway DJ, Blake P, Webb HA. A melatonin agonist and Nacetyl- $\mathrm{N}^{2}$-formyl-5-methoxykynurenamine accelerate the reentrainment of the melatonin rhythm following a phase advance of the light-dark cycle. Brain Res 1989; 495: 349-54.

[231] Budu A, Peres R, Bueno VB, Catalani LH, da Silva Garcia CR. $N^{1}$ acetyl- $N^{2}$-formyl-5-methoxykynuramine modulates the cell cycle of malaria parasites. J Pineal Res 2007, 42: 261-6.

[232] Ressmeyer A-R, Mayo JC, Zelosko V, et al. Antioxidant properties of the melatonin metabolite $N^{1}$-acetyl-5-methoxykynuramine $(\mathrm{AMK})$ : scavenging of free radicals and prevention of protein destruction. Redox Rep 2003; 8: 205-13.

[233] Burkhardt S, Reiter RJ, Tan D-X, Hardeland R, Cabrera J, Karbownik M. DNA oxidatively damaged by chromium(III) and $\mathrm{H}_{2} \mathrm{O}_{2}$ is protected by the antioxidants melatonin, $N^{1}$-acetyl- $N^{2}$-formyl-5methoxykynuramine, resveratrol and uric acid. Int J Biochem Cell Biol 2001; 33: 775-83

[234] Onuki J, Almeida EA, Medeiros MHG, Di Mascio P. Inhibition of 5-aminolevulinic acid-induced DNA damage by melatonin, $N^{1}$ acetyl- $N^{2}$-formyl-5-methoxykynuramine, quercetin or resveratrol. J Pineal Res 2005; 38: 107-15.

[235] Manda K, Ueno M, Anzai K. AFMK, a melatonin metabolite, attenuates X-ray-induced oxidative damage to DNA, proteins and lipids in mice. J Pineal Res 2007; 42: 386-93.

[236] Silva SO, Rodrigues MR, Ximenes VF, Bueno-da-Silva AE, Amarante-Mendes GP, Campa A. Neutrophils as a specific target for melatonin and kynuramines: effects on cytokine release. J Neuroimmunol 2004; 156: 146-52.

[237] Tan D-X, Manchester LC, Reiter RJ, Qi W-B, Karbownik M, Calvo JR. Significance of melatonin in antioxidative defense system: Reactions and products. Biol Signals Recept 2000; 9: 137-59.

[238] Seever K, Hardeland R. Novel pathway for $N^{\mathrm{l}}$-acetyl-5methoxykynuramine: UVB-induced liberation of carbon monoxide from precursor $N^{1}$-acetyl- $N^{2}$-formyl-5-methoxykynuramine. J Pineal Res 2008 Jan 9; [Epub ahead of print].

[239] Rosen J, Than NN, Koch D, Poeggeler B, Laatsch H, Hardeland R. Interactions of melatonin and its metabolites with the ABTS cation radical: extension of the radical scavenger cascade and formation of a novel class of oxidation products, C2-substituted 3indolinones. J Pineal Res 2006; 41: 374-81.

[240] Guenther AL, Schmidt SI, Laatsch H, et al. Reactions of the melatonin metabolite AMK ( $N^{1}$-acetyl-5-methoxykynuramine) with reactive nitrogen species: formation of novel compounds, 3acetamidomethyl-6-methoxycinnolinone and 3-nitro-AMK. J Pineal Res 2005; 39: 251-60.

[241] Hardeland R, Backhaus C, Fadavi A, Hess M. $N^{1}$-acetyl-5methoxykynuramine contrasts with other tryptophan metabolites by a peculiar type of NO scavenging: cyclization to a cinnolinone prevents formation of unstable nitrosamines. J Pineal Res 2007; 43 : $104-5$
[242] Hardeland R, Backhaus C, Fadavi A. Reactions of the NO redox forms $\mathrm{NO}^{+}, \cdot \mathrm{NO}$ and $\mathrm{HNO}$ (protonated $\mathrm{NO}^{-}$) with the melatonin metabolite $N^{1}$-acetyl-5-methoxykynuramine. J Pineal Res 2007; 43 : 382-8.

[243] Kelly RW, Amato F, Seamark RF. N-Acetyl-5-methoxy kynurenamine, a brain metabolite of melatonin, is a potent inhibitor of prostaglandin biosynthesis. Biochem Biophys Res Commun 1984; 121: 372-9

[244] Mayo JC, Sainz RM, Tan D-X, et al. Anti-inflammatory actions of melatonin and its metabolites, N1-acetyl-N2-formyl-5-methoxykynuramine (AFMK) and N1-acetyl-5-methoxykynuramine (AMK), in macrophages. J Neuroimmunol 2005; 165: 139-49.

[245] León J, Escames G, Rodríguez MI, et al. Inhibition of neuronal nitric oxide synthase activity by $N^{1}$-acetyl-5-methoxykynuramine, a brain metabolite of melatonin. J Neurochem 2006; 98: 2023-33

[246] Balzer I, Hardeland R. Action of kynuramine in a dinoflagellate: stimulation of bioluminescence in Gonyaulax polyedra. Comp Biochem Physiol 1989; 94C: 129-32.

[247] Hardeland R, Coto-Montes A, Poeggeler B. Circadian rhythms, oxidative stress, and antioxidative defense mechanisms. Chronobiol Int 2003; 20: 921-62.

[248] Fu L, Pelicano H, Liu J, Huang P, Lee C. The circadian gene period 2 plays an important role in tumor suppression and DNA damage response in vivo. Cell 2002; 111:41-50.

[249] Rosbach M, Takahashi JS. Circadian rhythms: The cancer connection. Nature 2002; 420: 373-4.

[250] Conti A. Oncology in neuroimmunomodulation. What progress has been made? Ann NY Acad Sci 2000; 917: 68-83.

[251] Guerrero JM, Reiter RJ. Melatonin-immune system relationships. Curr Top Med Chem 2002; 2: 167-79.

[252] Carrillo-Vico A, Reiter RJ, Lardone PJ, et al. The modulatory role of melatonin on immune responsiveness. Curr Opin Investig Drugs 2006; 7: 423-31

[253] Hardeland R, Pandi-Perumal SR, Cardinali DP. Molecules in focus — Melatonin. Int J Biochem Cell Biol 2006; 38: 313-6.

[254] Miller SC, Pandi-Perumal SR, Esquifino AI, Cardinali DP, Maestroni GJM. The role of melatonin in immuno-enhancement: potential application in cancer. Int J Exp Pathol 2006; 87: 81-7.

[255] Markus RP, Ferreira ZS, Fernandes PA, Cecon E. The immunepineal axis: a shuttle between endocrine and paracrine melatonin sources. Neuroimmunomodulation 2007; 14: 126-33.

[256] Altun A, Ugur-Altun B. Melatonin: therapeutic and clinical utilization. Int J Clin Pract 2007; 61: 835-45.

[257] García-Mauriño S, Pozo D, Carrillo-Vico A, Calvo JR, Guerrero JM. Melatonin activates Th1 lymphocytes by increasing IL-12 production. Life Sci 1999; 65: 2143-50.

[258] Carrillo-Vico A, García-Mauriño S, Calvo JR, Guerrero JM. Melatonin counteracts the inhibitory effect of PGE2 on IL-2 production in human lymphocytes via its mt1 membrane receptor. FASEB J 2003; 17: 755-7.

[259] Lotufo CM, Lopes C, Dubocovich ML, Farsky SH, Markus RP. Melatonin and $\mathrm{N}$-acetylserotonin inhibit leukocyte rolling and adhesion to rat microcirculation. Eur J Pharmacol 2001; 430: 351-7.

[260] Markowska M, Mrozkowiak A, Pawlak J, Skwar o-So ta K. Intracellular second messengers involved in melatonin signal transduction in chicken splenocytes in vitro. J Pineal Res 2004; 37: 207-12.

[261] López LC, Escames G, Tapias V, Utrilla P, León J, AcuñaCastroviejo D. Identification of an inducible nitric oxide synthase in diaphragm mitochondria from septic mice: its relation with mitochondrial dysfunction and prevention by melatonin. Int $\mathrm{J}$ Biochem Cell Biol 2006; 38: 267-78.

[262] Escames G, López LC, Tapias V, et al. Melatonin counteracts inducible mitochondrial nitric oxide synthase-dependent mitochondrial dysfunction in skeletal muscle of septic mice. J Pineal Res 2006; 40: 71-8

[263] Escames G, Acuña-Castroviejo D, López LC, et al. Pharmacological utility of melatonin in the treatment of septic shock: experimental and clinical evidence. J Pharm Pharmacol 2006; 58: 1153-65.

[264] Escames G, López LC, Ortiz F, et al. Attenuation of cardiac mitochondrial dysfunction by melatonin in septic mice. FEBS J 2007 274: 2135-47.

[265] Barlow-Walden LR, Reiter RJ, Abe M, et al. Melatonin stimulates brain glutathione peroxidase activity. Neurochem Int 1995; 26 : 497-502. 
[266] Pablos MI, Agapito MT, Gutierrez R, et al. Melatonin stimulates the activity of the detoxifying enzyme glutathione peroxidase in several tissues of chicks. J Pineal Res 1995; 19: 111-5.

[267] Pablos MI, Chuang J, Reiter RJ, et al. Time course of the melatonin-induced increase in glutathione peroxidase activity in chick tissues. Biol Signals 1995; 4: 325-30.

[268] Reiter RJ, Melchiorri D, Sewerynek E, et al. A review of the evidence supporting melatonin's role as an antioxidant. J Pineal Res 1995; 18: 1-11.

[269] Reiter RJ, Garcia JJ, Pie J. Oxidative toxicity in models of neurodegeneration: responses to melatonin. Restor Neurol Neurosci 1998; 12: 135-42.

[270] Reiter RJ. Oxidative damage in the central nervous system: Protection by melatonin. Prog Neurobiol 1998; 56: 359-84.

[271] Kotler M, Rodríguez C, Sáinz RM, Antolín I, Menéndez-Peláez A. Melatonin increases gene expression for antioxidant enzymes in rat brain cortex. J Pineal Res 1998; 24: 83-9.

[272] Reiter RJ, Tan D-X, Osuna C, Gitto E. Actions of melatonin in the reduction of oxidative stress. A review. J Biomed Sci 2000; 7: 44458.

[273] Mayo JC, Sainz RM, Antolin I, Herrera F, Martin V, Rodriguez C. Melatonin regulation of antioxidant enzyme gene expression. Cell Mol Life Sci 2002; 59: 1706-13.

[274] Balkan J, Sener G, Cevikbas U, Keyser-Uysal M, Uysal M. Melatonin improved the disturbances in hepatic prooxidant and antioxidant balance and hepatotoxicity induced by a cholesterol diet in C57BL/6J mice. Int J Vitam Nutr Res 2004; 74: 349-54.

[275] Gómez M, Esparza JL, Nogués MR, Giralt M, Cabré M, Domingo JL. Pro-oxidant activity of aluminum in the rat hippocampus: gene expression of antioxidant enzymes after melatonin administration. Free Radic Biol Med 2005; 38: 104-11.

[276] Liu F, Ng TB. Effect of pineal indoles on activities of the antioxidant defense enzymes superoxide dismutase, catalase, and glutathione reductase, and levels of reduced and oxidized glutathione in rat tissues. Biochem Cell Biol 2000; 78: 447-53.

[277] Antolín I, Rodríguez C, Sáinz RM, et al. Neurohormone melatonin prevents cell damage: effect on gene expression for antioxidant enzymes. FASEB J 1996; 10: 882-90.

[278] Ustundag B, Kazez A, Demirbag M, Canatan H, Halifeoglu I, Ozercan ICH. Protective effect of melatonin on antioxidative system in experimental ischemia-reperfusion of rat small intestine. Cell Physiol Biochem 2000; 10: 229-36.

[279] Öztürk G, Coșkun S, Erbaș D, Hasanoğlu E. The effect of melatonin on liver superoxide dismutase activity, serum nitrate and thyroid hormone levels. Jap J Physiol 2000; 50: 149-53.

[280] Wang H, Wei W, Shen YX, et al. Protective effect of melatonin against liver injury in mice induced by Bacillus Calmette-Guerin plus lipopolysaccharide. World J Gastroenterol 2004; 10: 2690-6.

[281] Taskiran D, Tanyalcin T, Sozmen EY, et al. The effects of melatonin on the antioxidant systems in experimental spinal injury. Int $\mathrm{J}$ Neurosci 2000; 104: 63-73.

[282] Uz T, Manev H. Circadian expression of pineal 5-lipoxygenase mRNA. Neuroreport 1998; 9: 783-6.

[283] Manev H, Uz T, Qu T. Early upregulation of hippocampal 5lipoxygenase following systemic administration of kainate to rats. Restor Neurol Neurosci 1998; 12: 81-5.

[284] Zhang H, Akbar M, Kim HY. Melatonin: an endogenous negative modulator of 12-lipoxygenation in the rat pineal gland. Biochem $\mathrm{J}$ 1999; 344, Pt 2: 487-93.

[285] Pozo D, Reiter RJ, Calvo JR, Guerrero JM. Physiological concentrations of melatonin inhibit nitric oxide synthase in rat cerebellum. Life Sci 1994; 55: PL455-60.

[286] Bettahi I, Pozo D, Osuna C, Reiter RJ, Acuña-Castroviejo D, Guerrero JM. Melatonin reduces nitric oxide synthase activity in rat hypothalamus. J Pineal Res 1996; 20: 205-10.

[287] Gilad E, Wong HR, Zingarelli B, et al. Melatonin inhibits expression of the inducible isoform of nitric oxide synthase in murine macrophages: role of inhibitions of NFKB activation. FASEB J 1998; 12: 685-93.

[288] Chang HM, Ling EA, Chen CF, Lue H, Wen CY, Shieh JY. Melatonin attenuates the neuronal NADPH-d/NOS expression in the nodose ganglion of acute hypoxic rats. J Pineal Res 2002; 32: 65-73.

[289] Reiter RJ, Tan D-X, Burkhardt S. Reactive oxygen and nitrogen species and cellular and organismal decline: amelioration with melatonin. Mech Ageing Dev 2002; 123: 1007-19.
[290] Rogério F, de Souza Queiroz L, Teixeira SA, Oliveira AL, de Nucci G, Langone F. Neuroprotective action of melatonin on neonatal rat motoneurons after sciatic nerve transection. Brain Res 2002; 926: 33-41.

[291] Storr M, Koppitz P, Sibaev A, et al. Melatonin reduces nonadrenergic, non-cholinergic relaxant neurotransmission by inhibition of nitric oxide synthase activity in the gastrointestinal tract of rodents in vitro. J Pineal Res 2002; 33: 101-8.

[292] Tamura EK, Silva CL, Markus RP. Melatonin inhibits endothelial nitric oxide production in vitro. J Pineal Res 2006; 41: 267-74.

[293] Rogério F, Teixeira SA, Júnior HJ, et al. mRNA and protein expression and activities of nitric oxide synthases in the lumbar spinal cord of neonatal rats after sciatic nerve transection and melatonin administration. Neurosci Lett 2006; 407: 182-7.

[294] Zwirska-Korczala K, Jochem J, Adamczyk-Sowa M, et al. Influence of melatonin on cell proliferation, antioxidative enzyme activities and lipid peroxidation in 3T3-L1 preadipocytes - an in vitro study. J Physiol Pharmacol 2005; 56(Suppl 6): 91-9

[295] Rezzani R, Rodella LF, Bonomini F, Tengattini S, Bianchi R, Reiter RJ. Beneficial effects of melatonin in protecting against cyclosporine A-induced cardiotoxicity are receptor mediated. J Pineal Res 2006; 41: 288-95.

[296] Esposito E, Iacono A, Muià C, et al. Signal transduction pathways involved in protective effects of melatonin in C6 glioma cells. J Pineal Res 2008; 44: 78-87.

[297] Alonso M, Collado PS, González-Gallego J. Melatonin inhibits the expression of the inducible isoform of nitric oxide synthase and nuclear factor kappa B activation in rat skeletal muscle. J Pineal Res 2006; 41: 8-14.

[298] Quiroz Y, Ferrebuz A, Romero F, Vaziri ND, Rodriguez-Iturbe B. Melatonin ameliorates oxidative stress, inflammation, proteinuria and progression of renal damage in rats with renal mass reduction. Am J Physiol Renal Physiol 2007 Dec 12; [Epub ahead of print].

[299] Wang H, Wei W, Wang NP, et al. Melatonin ameliorates carbon tetrachloride-induced hepatic fibrogenesis in rats via inhibition of oxidative stress. Life Sci 2005; 77: 1902-15.

[300] Kratsovnik E, Bromberg Y, Sperling O, Zoref-Shani E. Oxidative stress activates transcription factor NF- $\kappa \mathrm{B}$-mediated protective signaling in primary rat neuronal cultures. J Mol Neurosci 2005; 26: 27-32.

[301] Chetsawang B, Putthaprasart C, Phansuwan-Pujito P, Govitrapong $\mathrm{P}$. Melatonin protects against hydrogen peroxide-induced cell death signaling in SH-SY5Y cultured cells: involvement of nuclear factor kappa B, Bax and Bcl-2. J Pineal Res 2006; 41: 116-23.

[302] Jang MH, Jung SB, Lee MH, et al. Melatonin attenuates amyloid $\beta_{25-35}$-induced apoptosis in mouse microglial BV2 cells. Neurosci Lett 2005; 380: 26-31.

[303] Beni SM, Kohen R, Reiter RJ, Tan D-X, Shohami E. Melatonininduced neuroprotection after closed head injury is associated with increased brain antioxidants and attenuated late-phase activation of NF-kappaB and AP-1. FASEB J 2004; 18: 149-51.

[304] Martín V, Herrera F, Carrera-Gonzalez P, et al. Intracellular signaling pathways involved in the cell growth inhibition of glioma cells by melatonin. Cancer Res 2006; 66: 1081-8.

[305] Mazzon E, Esposito E, Crisafulli C, et al. Melatonin modulates signal transduction pathways and apoptosis in experimental colitis J Pineal Res 2006; 41: 363-73.

[306] Sainz RM, Mayo JC, Reiter RJ, Antolin I, Esteban MM, Rodriguez C. Melatonin regulates glucocorticoid receptor: an answer to its antiapoptotic action in thymus. FASEB J 1999; 13: 1547-56.

[307] Hoijman E, Rocha Viegas L, Keller Sarmiento MI, Rosenstein RE, Pecci A. Involvement of Bax protein in the prevention of glucocorticoid-induced thymocytes apoptosis by melatonin. Endocrinology 2004; 145: 418-25.

[308] Presman DM, Hoijman E, Ceballos NR, Galigniana MD, Pecci A. Melatonin inhibits glucocorticoid receptor nuclear translocation in mouse thymocytes. Endocrinology 2006; 147: 5452-9.

[309] Marinova C, Persengiev S, Konakchieva R, Ilieva A, Patchev V. Melatonin effects on glucocorticoid receptors in rat brain and pituitary: significance in adrenocortical regulation. Int J Biochem 1991; 23: 479-81.

[310] Persengiev SP. Multiple domains of melatonin receptor are involved in the regulation of glucocorticoid receptor-induced gene expression. J Steroid Biochem Mol Biol 1999; 68: 181-7.

[311] Persengiev SP. The neuroprotective and antiapoptotic effects of melatonin in cerebellar neurons involve glucocorticoid receptor and 
p130 signal pathways. J Steroid Biochem Mol Biol 2001; 77: 1518.

[312] Kim MJ, Kim HK, Kim BS, Yim SV. Melatonin increases cell proliferation in the dentate gyrus of maternally separated rats. J Pineal Res 2004; 37: 193-7.

[313] Persengiev SP, Kondova II. Tissue-specific modulation of rat glucocorticoid receptor binding activity by melatonin. Experientia 1993; 49: 332-4

[314] Kiefer TL, Lai L, Yuan L, Dong C, Burow ME, Hill SM. Differential regulation of estrogen receptor alpha, glucocorticoid receptor and retinoic acid receptor alpha transcriptional activity by melatonin is mediated via different G proteins. J Pineal Res 2005; 38 : 231-9.

[315] Blackhurst G, McElroy PK, Fraser R, Swan RL, Connell JM. Seasonal variation in glucocorticoid receptor binding characteristics in human mononuclear leucocytes. Clin Endocrinol (Oxford) 2001; 55: 683-8.

[316] Pratt WB, Silverstein AM, Galigniana MD. A model for the cytoplasmic trafficking of signalling proteins involving the hsp90binding immunophilins and p50cdc37. Cell Signal 1999; 11: 83951.

[317] Ratajczak T, Ward BK, Minchin RF. Immunophilin chaperones in steroid receptor signalling. Curr Top Med Chem 2003; 3: 1348-57.

[318] Antolín I, Hardeland R. In: Hardeland R, Ed. Suppression of the Gonyaulax glow peak by paraquat and its restoration by melatonin. In: Biological Rhythms and Antioxidative Protection. Cuvillier, Göttingen, 1997; 86-97.

[319] Hardeland R, Coto-Montes A. In: Pandalai SG, Ed. Chronobiology of oxidative stress and antioxidative defense mechanisms. In: Recent Research Developments in Comparative Biochemistry and Physiology, Vol 1, Transworld Research Network, Trivandrum, 2000; 123-37.

[320] Poeggeler B, Thuermann S, Dose A, Schoenke M, Burkhardt S, Hardeland R. Melatonin's unique radical scavenging properties roles of its functional substituents as revealed by a comparison with its structural analogs. J Pineal Res 2002; 33: 20-30.

[321] Semak I, Naumova M, Korik E, Terekhovich V, Wortsman J, Slominski A. A novel metabolic pathway of melatonin: oxidation by cytochrome C. Biochemistry 2005; 44: 9300-7.

[322] Vygodina TV, Konstantinov AA. Peroxidase activity of mitochondrial cytochrome c oxidase. Biochemistry (Moscow) 2007; 72: 1056-64.

[323] Srinivasan V, Pandi-Perumal SR, Maestroni GJM, Esquifino AI, Hardeland R, Cardinali DP. Role of melatonin in neurodegenerative diseases. Neurotox Res 2005; 7: 293-318.

[324] Absi E, Ayala A, Machado A, Parrado J. Protective effect of melatonin against the 1-methyl-4-phenylpyridinium-induced inhibition of complex I of the mitochondrial respiratory chain. J Pineal Res 2000; 29: 40-7.

[325] Khaldy H, Escames G, León J, Bikjdaouene L, Acuña-Castroviejo D. Synergistic effects of melatonin and deprenyl against MPTPinduced mitochondrial damage and DA depletion. Neurobiol Aging 2003; 24: 491-500.

[326] Martín M, Macías M, León J, Escames G, Khaldy H, AcuñaCastroviejo D. Melatonin increases the activity of the oxidative phosphorylation enzymes and the production of ATP in rat brain and liver mitochondria. Int J Biochem Cell Biol 2002; 34: 348-57.

[327] Okatani Y, Wakatsuki A, Reiter RJ. Melatonin protects hepatic mitochondrial respiratory chain activity in senescence-accelerated mice. J Pineal Res 2002; 32: 143-8.

[328] Okatani Y, Wakatsuki A, Reiter RJ, Miyahara Y. Hepatic mitochondrial dysfunction in senescence-accelerated mice: correction by long-term, orally administered physiological levels of melatonin. J Pineal Res 2002; 33: 127-33.

[329] Okatani Y, Wakatsuki A, Reiter RJ, Miyahara Y. Acutely administered melatonin restores hepatic mitochondrial physiology in old mice. Int J Biochem Cell Biol 2003; 35: 367-75.

[330] Acuña-Castroviejo D, Escames G, León J, Carazo A, Khaldy H. Mitochondrial regulation by melatonin and its metabolites. Adv Exp Med Biol 2003; 527: 549-57.

[331] León J, Acuña-Castroviejo D, Escames G, Tan D-X, Reiter RJ. Melatonin mitigates mitochondrial malfunction. J Pineal Res 2005; 38: 1-9.

[332] López LC, Escames G, Ortiz F, Ros E, Acuña-Castroviejo D. Melatonin restores the mitochondrial production of ATP in septic mice. Neuroendocrinol Lett 2006; 27: 623-30.
[333] Leon J, Acuña-Castroviejo D, Sainz RM, Mayo JC, Tan D-X, Reiter RJ. Melatonin and mitochondrial function. Life Sci 2004; 75: 765-90.

[334] Acuña-Castroviejo D, Escames G, Rodríguez MI, López LC. Melatonin role in the mitochondrial function. Front Biosci 2007; 12: 947-63.

[335] Pandi-Perumal SR, Zisapel N, Srinivasan V, Cardinali DP. Melatonin and sleep in aging population. Exp Gerontol 2005; 40: 911 25 .

[336] Pandi-Perumal SR, Srinivasan V, Poeggeler B, Hardeland R, Cardinali DP. Drug insight: the use of melatonergic agonists for the treatment of insomnia-focus on ramelteon. Nat Clin Pract Neurol 2007; 3: 221-8

[337] Pandi-Perumal SR, Srinivasan V, Spence DW, Cardinali DP. Role of the melatonin system in the control of sleep: therapeutic implications. CNS Drugs 2007; 21: 995-1018.

[338] Golombek DA, Escolar E, Cardinali DP. Melatonin-induced depression of locomotor activity in hamsters: time-dependency and inhibition by the central-type benzodiazepine antagonist Ro 151788. Physiol Behav 1991; 49: 1091-7.

[339] Golombek DA, Fernández Duque D, De Brito Sánchez MG, Burin L, Cardinali DP. Time-dependent anticonvulsant activity of melatonin in hamsters. Eur J Pharmacol 1992; 210: 253-8.

[340] Golombek DA, Escolar E, Burin LJ, De Brito Sánchez MG, Fernández Duque D, Cardinali DP. Chronopharmacology of melatonin: inhibition by benzodiazepine antagonism. Chronobiol Int 1992; 9: 124-31.

[341] Jahnke G, Marr M, Myers C, Wilson R, Travlos G, Price C. Maternal and developmental toxicity evaluation of melatonin administered orally to pregnant Sprague-Dawley rats. Toxicol Sci 1999; 50: 271-9.

[342] Pang CS, Tsang SF, Yang JC. Effects of melatonin, morphine and diazepam on formalin-induced nociception in mice. Life Sci 2001; 68: 943-51.

[343] Papp M, Litwa E, Gruca P, Mocaër E. Anxiolytic-like activity of agomelatine and melatonin in three animal models of anxiety. Behav Pharmacol 2006; 17: 9-18.

[344] Mantovani M, Kaster MP, Pertile R, Calixto JB, Rodrigues ALS, Santos ARS. Mechanisms involved in the antinociception caused by melatonin in mice. J Pineal Res 2006; 41: 382-389.

[345] Ulugol A, Dokmeci D, Guray G, Sapolyo N, Ozyigit F, Tamer M. Antihyperalgesic, but not antiallodynic, effect of melatonin in nerve-injured neuropathic mice: Possible involvements of the Larginine-NO pathway and opioid system. Life Sci 2006; 78: 15927.

[346] Muñoz-Hoyos A, Sánchez-Forte M, Molina-Carballo A, et al. Acuña-Castroviejo D. Melatonin's role as an anticonvulsant and neuronal protector: experimental and clinical evidence. J Child Neurol 1998; 13: 501-9.

[347] Tanaka D, Furusawa K, Kameyama K, Okamoto H, Doi M. Melatonin signaling regulates locomotion behavior and homeostatic states through distinct receptor pathways in Caenorhabditis elegans. Neuropharmacology 2007; 53: 157-68.

[348] Molina-Carballo A, Muñoz-Hoyos A, Sánchez-Forte M, UberosFernández J, Moreno-Madrid F, Acuña-Castroviejo D. Melatonin increases following convulsive seizures may be related to its anticonvulsant properties at physiological concentrations. Neuropediatrics 2007; 38: 122-5.

[349] Prada C, Udin SB, Wiechmann AF, Zhdanova IV. Stimulation of melatonin receptors decreases calcium levels in Xenopus tectal cells by activating $\mathrm{GABA}_{\mathrm{C}}$ receptors. J Neurophysiol 2005; 94: 968-78.

[350] Prada C, Udin SB. Melatonin decreases calcium levels in retinotectal axons of Xenopus laevis by indirect activation of group III metabotropic glutamate receptors. Brain Res 2005; 1053. 67-76.

[351] Liu LY, Hoffman GE, Fei XW, Li Z, Zhang ZH, Mei YA. Delayed rectifier outward $\mathrm{K}^{+}$current mediates the migration of rat cerebellar granule cells stimulated by melatonin. J Neurochem 2007; 102: 333-44.

[352] Zhang M, Cao LH, Yang XL. Melatonin modulates glycine currents of retinal ganglion cells in rat. Neuroreport 2007; 18: 1675-8.

[353] Acuña-Castroviejo D. La melatonina y los mecanismos de inhibición en el SNC. In: Rodríguez Sánchez C, Rodríguez Colunga MJ, Eds. Melatonina: Mecanismos de acción e implicaciones terapéuticas; 1994 Dec 15-16; Universidad de Oviedo, Oviedo (Asturias); 1994; resumen no 10 . 
[354] Peled N, Shorer Z, Peled E, Pillar G. Melatonin effect on seizures in children with severe neurologic deficit disorders. Epilepsia 2001; 42: $1208-10$

[355] Saracz J, Rosdy B. [Effect of melatonin on intractable epilepsies] (Hungarian) Orv Hetil 2004; 145: 2583-7.

[356] Bazil CW, Short D, Crispin D, Zheng W. Patients with intractable epilepsy have low melatonin, which increases following seizures. Neurology 2000; 55: 1746-8.

[357] Rai S, Haldar C. Pineal control of immune status and hematological changes in blood and bone marrow of male squirrels (Funambulus pennanti) during their reproductively active phase. Comp Biochem Physiol 2003; 136C: 319-28.

[358] Haldar C, Rai S, Singh R. Melatonin blocks dexamethasoneinduced immunosuppression in a seasonally breeding rodent Indian palm squirrel, Funambulus pennanti. Steroids 2004; 69: 367-77.

[359] Singh SS, Haldar C. Melatonin prevents testosterone-induced suppression of immune parameters and splenocyte proliferation in Indian tropical jungle bush quail, Perdicula asiatica. Gen Comp Endocrinol 2005; 141: 226-32.

[360] Rai S, Haldar C, Singh SS. Trade-off between L-thyroxin and melatonin in immune regulation of the Indian palm squirrel, Funambulus pennanti, during the reproductively inactive phase. Neuroendocrinology 2005; 82: 103-10.

[361] Majewski P, Adamska I, Pawlak J, Barańska A, Skwarło-Sońta K. Seasonality of pineal gland activity and immune functions in chickens. J Pineal Res 2005; 39: 66-72.

[362] Singh SS, Haldar C. Peripheral melatonin modulates seasonal immunity and reproduction of Indian tropical male bird Perdicula asiatica. Comp Biochem Physiol 2007; 146A: 446-50.

[363] Picinato MC, Hirata AE, Cipolla-Neto J, et al. Activation of insulin and IGF-1 signaling pathways by melatonin through MT1 receptor in isolated rat pancreatic islets. J Pineal Res 2008; 44: 88-94.

[364] Ramracheya RD, Muller DS, Squires PE, et al. Function and expression of melatonin receptors on human pancreatic islets. J Pineal Res 2008 Jan 9; [Epub ahead of print].

[365] Peschke E. Melatonin, endocrine pancreas and diabetes. J Pineal Res 2008; 44: 26-40.

[366] Robeva R, Kirilov G, Tomova A, Kumanov P. Melatonin-insulin interactions in patients with metabolic syndrome. J Pineal Res 2008; 44: 52-6.

[367] Niles LP, Armstrong KJ, Rincón Castro LM, et al. Neural stem cells express melatonin receptors and neurotrophic factors: colocalization of the MT1 receptor with neuronal and glial markers. BMC Neurosci 2004 Oct 28. 5: article no 41 [8 screens]. Available from $\mathrm{http}: / /$ www.biomedcentral.com/1471-2202/5/41.

[368] Castro LM, Gallant M, Niles LP. Novel targets for valproic acid: up-regulation of melatonin receptors and neurotrophic factors in C6 glioma cells. J Neurochem 2005; 95: 1227-36.
[369] Kong X, Li X, Cai Z, et al. Melatonin regulates the viability and differentiation of rat midbrain neural stem cells. Cell Mol Neurobiol 2007 Oct 3; [Epub ahead of print].

[370] Weishaupt JH, Bartels C, Pölking E, et al. Reduced oxidative damage in ALS by high-dose enteral melatonin treatment. J Pineal Res 2006; 41: 313-23.

[371] Anisimov VN, Alimova IN, Baturin DA, et al. Dose-dependent effect of melatonin on life span and spontaneous tumor incidence in female SHR mice. Exp Gerontol 2003; 38: 449-61.

[372] Semenchenko GV, Anisimov VN, Yashin AI. Stressors and antistressors: how do they influence life span in HER-2/neu transgenic mice? Exp Gerontol 2004; 39: 1499-511.

[373] Poeggeler B. Neuroprotection by indole and nitrone compounds acting as mitochondrial metabolism modifiers with potent antioxidant activity. Neurobiol Aging 2004; 25(Suppl 2): S587-8.

[374] Poeggeler B. Melatonin, aging, and age-related diseases: perspectives for prevention, intervention, and therapy. Endocrine 2005; 27: 201-12.

[375] Vivanco P, Ortiz V, Rol MA, Madrid JA. Looking for the keys to diurnality downstream from the circadian clock: role of melatonin in a dual-phasing rodent, Octodon degus. J Pineal Res 2007; 42: 280-90.

[376] Weinert D. Age-dependent changes of the circadian system. Chronobiol Int 2000; 17: 261-83.

[377] Hurd MW, Ralph MR. The significance of circadian organization for longevity in the golden hamster. J Biol Rhythms 1998; 13: 4306.

[378] Escames G, López LC, Ortiz F, Ros E, Acuña-Castroviejo D. Agedependent lipopolysaccharide-induced iNOS expression and multiorgan failure in rats: effects of melatonin treatment. Exp Gerontol 2006; 41: 1165-73.

[379] Rodríguez MI, Escames G, López LC, et al. Chronic melatonin treatment reduces the age-dependent inflammatory process in senescence-accelerated mice. J Pineal Res 2007; 42: 272-9.

[380] Karasek M, Reiter RJ. Melatonin and aging. Neuroendocrinol Lett 2002; 23, Suppl 1: 14-6.

[381] Reiter RJ, Tan DX, Mayo JC, Sainz RM, Lopez-Burillo S. Melatonin, longevity and health in the aged: an assessment. Free Radic Res 2002; 36: 1323-9.

[382] Rodríguez MI, Carretero M, Escames G, et al. Chronic melatonin treatment prevents age-dependent cardiac mitochondrial dysfunction in senescence-accelerated mice. Free Radic Res 2007; 41: 1524.

[383] Rodriguez MI, Escames G, López LC, et al. Melatonin administration prevents cardiac and diaphragmatic mitochondrial oxidative damage in senescence-accelerated mice. J Endocrinol 2007; 194: $637-43$.

(C) Hardeland and Poeggeler; Licensee Bentham Open.

This is an open access article distributed under the terms of the Creative Commons Attribution License (http://creativecommons.org/licenses/by/2.5/), which permits unrestrictive use, distribution, and reproduction in any medium, provided the original work is properly cited. 